\title{
Reactive Power Market-Management Considering Uncertainties of Load and Power of Wind Powerhouses
}

\author{
Akbar Sharifi Ziarati ${ }^{1}$, Mojtaba Najafi ${ }^{2}$ \\ ${ }^{I}$ MA Student, power electric engineering, Islamic Azad University science and research branch, Bushehr, Iran, \\ ${ }^{2}$ Ph.D., power electric engineering, Islamic Azad University science and research branch, \\ bushehr, Iran,
}

*Corresponding Author: Akbar Sharifi Ziarati, MA Student, power electric engineering, Islamic Azad Universitv science and research branch. Bushehr. Iran.

\begin{abstract}
Despite traditional power generation based on fossil fuel, renewable energies like wind have primary uncontrollable energies including wide speed. In line with increasing the number of wind turbines connected to distribution system, the grid operator pays much attention to how these accidental resources can affect grid loss. To this end, Common methods are according to certain analysis which is not capable of appropriately assessing the performance of the system in permanent status. It is possible to have a better assessment through analyzing probabilities and considering the accidental behavior of grid data including wind power and consuming load. In this paper, it is attempted to determine the reactive power market and its pricing with a look at economic, technical concerns. Firstly, reactive power market model will be introduced; wind power and accidental models of consuming load will be represented. Then, the performance of power system in permanent status, the performance of productive units in short-term markets of reactive power will be taken into consideration. It is worth mentioning that a huge amount of represented articles talking around this matter mostly have focused on pricing the reactive power. Therefore, the main focus of the present study is on reactive power market and its development in a way that simultaneous analysis of uncertainty parameters (load and wind power demanded from the grid) and their influences on reactive power market will be performed. To model accidental behavior of productive power of wind turbines, limited ARIMA (LARIMA) method is adopted. The important point of using this special method to reach precise results and getting a more realistic model is mutual correlation between wind farms located in neighboring sites and the model. Further, to model behavioral changes of grid consuming load, AR(12) method is used followed by Monte-Carlo method in order to build power generation scenarios. By implementing suggested method on the sample grid, it is possible to assess the algorithm influence.
\end{abstract}

Keywords: accidental optimization, wind turbines, accidental model, reactive power market management

\section{INTRODUCTION}

In retail economics, optimization procedures are based on maximization principle of benefit amount in an economic activity. In a totally competitive market, benefit is maximized when marginal revenue is equal to marginal cost. Spot pricing, or in other word "Actual Marginal Pricing", makes a correct economic signal while maintaining balance between generation and demand in power system, as well as recognizing the status of producers and consumers in the market. Spot pricing theory can be used for pricing the actual time of reactive power by making use of a revised optimized load-distribution plan. In 1991, Martin et al. [1], for the first time, determined the marginal price of reactive power and reactive in each favorable node of the system by using Lagrange coefficient. Marginal pricing for reactive power, however, is not possible in practice due to great changes and unpredictability. Furthermore, pricing based on marginal cost is needed to be compatible with the system demands in order to be able to compensate the expenses [1-3]. In some papers, reactive power pricing is studied in form of pricing specification issue. Reactive power tracking, graph theory and method of using nodal Admittance matrix are all samples of this way of pricing. It is believed that reactive power pricing and management heavily depend on two important matters: the functional unbundling of facilities supporting it and voltage control services and, grid rules to enhance the association of generation and transmission systems for a reliable system operation [14].

International Journal of Research Studies in Electrical and Electronics Engineering (IJRSEEE) Page | 33 
The main objective of these methods is finding productive reactive power share of each generator for considering load and, hence, determining the amount of money allocated for each generator. Due to simultaneous transmission of active and reactive powers in lines, however, the precise amount of participation of each unit is difficult to determine and, to some extents, is subjective [4-7]. Reactive power costs include explicit and implicit costs. Explicit costs are the ones which must be directly paid. Primary investment and reactive power generation costs belong to this category. Implicit costs, in fact, are related to the costs of generators' lost opportunities. Generator might be ordered by the system independent beneficiary to increase its amount of reactive power generation until the generator has to decrease its active power generation due to capacity limitation. In this case, the generator misses a part of the revenue resulted from its active power sale. This loss must be paid. Accordingly, the money paid to the generators due to this loss is called Lost Opportunity Cost [8].

Node pricing is another kind of pricing structures which is the sensitivity of generators' generation cost related to the amount of reactive power demand which is usually calculated by means of optimized load distribution [9]. Generation cost only includes variable costs that vary depending on fuel cost. The significant difference between active and reactive power cost is that reactive power variable costs are low and usually negligible. In other words, this way of pricing simply determine a little volume of reactive power actual price. In an appropriately-designed market, this price is relatively lower than $1 \%$ of the actual power price. Additionally, this price is greatly variable and the investment costs of reactive power compensation are not considered in this process. Therefore, collectively, reactive power node pricing is not effective enough.

Due to negligibility of reactive power generation costs, current capacity available to reactive power must be taken into account as part of reactive power cost. This way, the possibility of playing a game among generators by flowing reactive power among them is effectively inhibited. As an instance, in England, firstly around $80 \%$ of the total cost was allocated for available cost of reactive power generation and the rest $20 \%$ for reactive power generation cost in order for compensation. Afterwards, the capacity cost was gradually decreasing and the generator's reactive power generation cost was more taken into account. This policy was taken due to encourage generators to produce reactive power and to this that producers do not consent simply to the given money of the capacity cost [10].

Beside the above-mentioned matters, and despite traditional systems in which the generation part is majorly based on fossil fuels, employing renewable energy sources in novel power grids including wind powered generation and solar energy (photovoltaic) have created new control problems for the grid resulted from accidental behavior of these energy sources (the accidental change in wind speed and the amount of sunshine). Employing these sources made new uncertainties in issues related to employing and deciding on distribution grids. For example, the power generated by a photovoltaic network with intermittent cloud coverage varies by $15 \%$ of its nameplate capacity in only 1 minute [23]. Bus voltage magnitudes in distribution grids are significantly influenced by active power variations. On a clear day, solar generation might simply go beyond local demand [24].

Though certain analysis is a common method in assessing power systems matters, adopting power system analysis methods according to uncertainty views (regarding current uncertainties) have taken into consideration by many sources [11]. Examples of implementing these uncertainty views in analyzing grid in form of issues like evaluating the reliability of grid, planning and developing transfer grid assuming uncertainty parameters, calculating stochastic load distribution, analyzing short connection surface in them and other relevant arguments related to stochastic reliability of the system is classifiable. The methods adopted for such stochastic analysis based on basic probabilistic theories related to accidental variables are single-variable and the methods of accidental analysis are multivariate.

\section{LITERATURE REVIEW}

In last two decades, renewable energy systems (with main focus on wind generation) began to attract more attention due to this fact that they are freely accessible, clean and capable to be extended. The amount of power obtained from wind turbines is gradually raising because of the increasinglyinstalled large wind farms around the world [20]. Due to the variable nature of wind, many problems have aroused in managing electrical grids [21]. Accordingly, the grid codes have been revised to meet 
the requirements of best performance of transmission systems. Specific control structures for wind turbines are presently in hand including real power control and reactive power control [20]. According to [15] and [16], the economic reactive cost function and pricing is not well-defined yet. In another words, the relationship between generating real electric power and reactive power is not taken into full consideration.

[17] Declare that an accurate pricing method for reactive power is essential in the electricity market as well, which is not possible through present optimal power flow models. In direction of previouslymentioned matters, they also believe that the generation cost of reactive power is ignored in these models. Hence, they adopt a sequential quadratic programming method to solve the optimal problem.

In [22] a stochastic reactive power market is introduced which incorporates plug-in hybrid electric vehicles (PHEVs) in this market. The uncertainty of PHEVs is considered in the stochastic marketclearing scheme as well. They also adopt Monte-Carlo simulation to generate random scenarios in a 17-node microgrid. In another study, authors propose a stochastic reactive power management in microgrids with renewables. As stated in [25], reactive power management tries to control reactive injections in a way that power loss over distribution lines is minimized while keeping bus voltage magnitudes within the pre-defined limits. In [25], authors make a stochastic framework for reactive power management considering a radial microgrid where distributed generation units with reactive power control capabilities are incorporated.

Distributed generators (DG) absorb or inject reactive power in order to regulate voltage and optimize the operation of the grid. Though many control plans assumed fixed DG power limits, reactive limits vary depending on the actual generator active power and terminal voltage [18]. Actual reactive power limits is calculated by generator parameters and their respective limiting factors [19]. Authors in [18] adopt a simplified method to calculate reactive power limits of distributed generators based on parameterized generic capability curves. The curves are made of 8 points which are extracted from the actual capability curves for 2 various terminal voltages. They further used interpolation for calculating the limits of generator reactive power.

Compared to our RTS 24-bus grid on which our results will be implemented, [26] proposed multizone DA-RPMS model tested and comapred with single-zone DA-RPMS model on Standard IEEE 24-bus reliability test system. They optimized simultaneously 3 functions: Total Payment Function (TFP), Total Real Transmission Loss (TRTL), and Voltage Stability Enhancement Index (VSEI).

The problem of optimal reactive power compensation for minimizing the power distribution losses in a smart microgrid is considered in [27]. Firstly, an approximate model of power distribution network is introduced. Then, the problem of ordering micro-generators to get to the optimal injection of reactive power is taken into consideration. In this regard, they designed a randomized optimization algorithm to show how a distributed approach is possible in case of having a partial knowledge about them problem parameters and of the status.

In this paper, it is attempted to assess the reactive power market and its pricing regarding economic and technical concerns. A point which is worth mentioning is that most published articles about this matter often paid attention to reactive power pricing issue. Hence, the main focus of the present study is on reactive power market and its development in a way that beside grid technical issues, the performance process of productive units in reactive power market will be assessed, as well as considering uncertainty parameters. First, a model is represented for reactive power market and then, the revised Total Payment Function (rTPF) is explained. After that, the conditions relating to load distribution, reactive power market settlement, the security of nodes' voltage, lines' current and the functional area of each unit will be explained followed by modeling the productive power of wind turbines by means of LARIMA method and considering the reciprocal correlation of wind farms, as well as consuming load changes. Finally, the results will be implemented on RTS 24-busgrid and the findings will be discussed. 


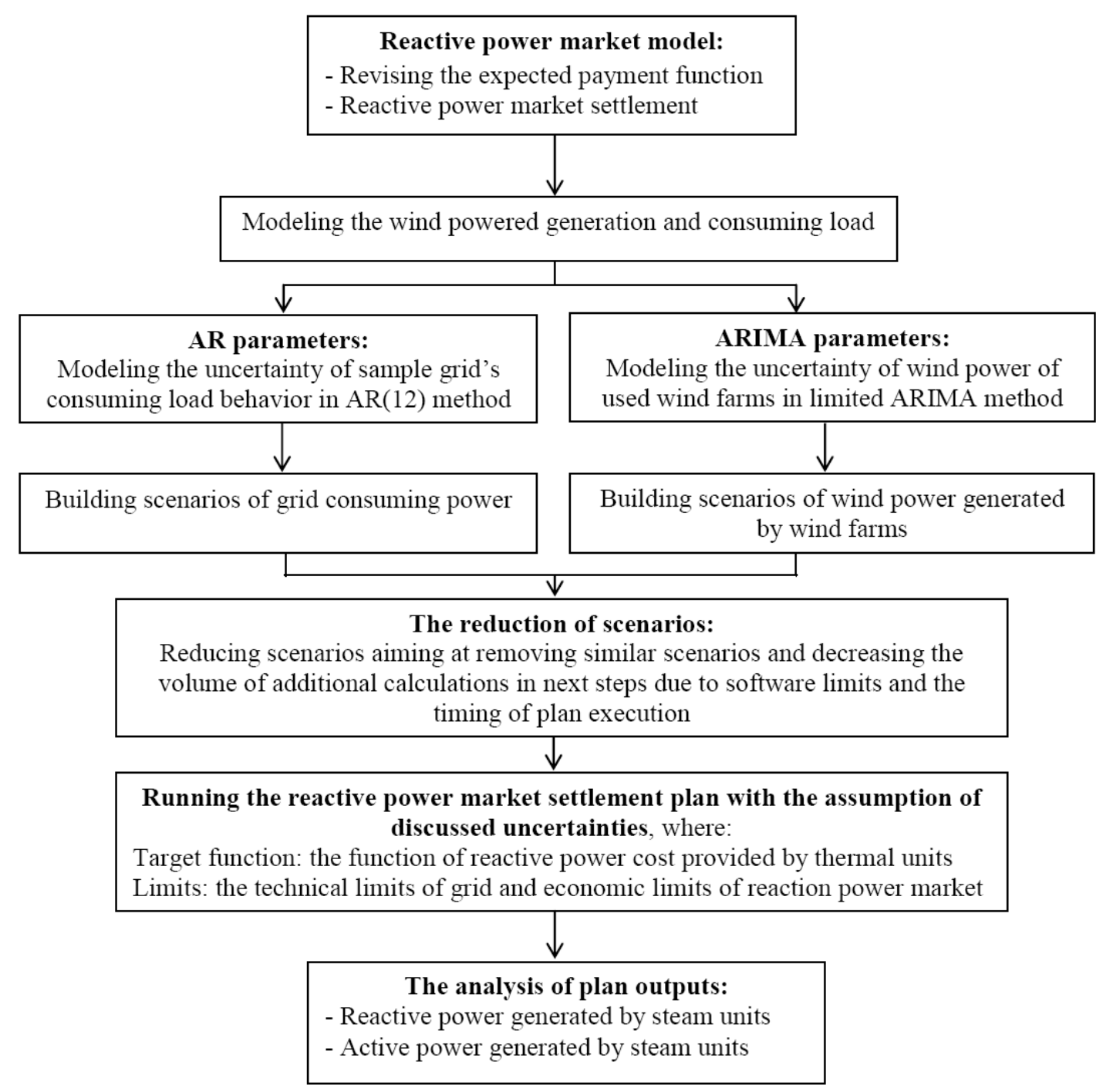

Figure1. The steps of article procedure

\section{Reactive Power Market Model}

Appropriate reactive power pricing entails full consideration of power system and reactive/active power sources, as well. The precise model of active and reactive power costs creates a fair pricing; hence, the producers can participate in electricity market with confidence and high motivation. Further, consumers will be encouraged to use electricity energy sufficiently. This situation leads to development and improvement of power system and a rise in social welfare. If the price of reactive power is set lower than the real price, the producers will not be motivated enough to use their full capability to generate reactive power. On the other side, due to the low price of reactive power, consumers will increase their demand of reactive power. As a result, insufficient amount of generated reactive power of units on one side, and increasing demand for reactive power of loads on the other side result in decreasing the possibility of reactive power transmission, system reliability and, finally, voltage collapse. Conversely, when the power reactive price is considered higher than the real price, producers show more tendency to generate reactive power when consumers decrease their reactive power consumption due to its high price. In this case, surplus reactive power existent in the system creates instability problems. Therefore, reactive power price must be set as precise and fair as possible.

Reactive power price is directly related to the location of generation since despite active power whose place of generation is not important, it is not favorable to generate reactive power in a place far from consumer even at low price. As a result, setting a price of equal value for all parts of power system in generating reactive power regardless of its location is not mostly taken into consideration; rather, the 
regional price of reactive power is desirable. Another point is that, despite active power, reactive power generation does not include fuel cost. However, primary investment costs paid by reactive power compensators - generators and synchronous condenser in particular - are high. Accordingly, though reactive power generation costs is lower than active power, it is necessary to take the compensators' primary investment costs into account when pricing reactive power.

Due to severe dependence of voltage profile on reactive power, the system exploiter might have to set the reactive power price higher than the actual one to maintain the system integration and voltage stability. In other words, reactive power pricing is a multi-objective procedure which must consider all influential factors when setting the price. It is worth noting that reactive power pricing is not according to the provisions ruling over logical active power pricing; although in some studies this method is used. In this section and based on what is stated in papers, reactive power pricing is assessed from different facets followed by a more precise evaluation of reactive power market.

\subsection{The Revision of Expected Payment Function}

[11] states the structure of expected payment function for ith generator in form of the following equation:

$$
E P F_{i}=a_{0 i}+\int_{Q_{\text {Min }}}^{0} m_{1 i} \cdot d Q_{i}+\int_{Q_{B a s e}}^{Q_{A}} m_{2 i} \cdot d Q_{i}+\int_{Q_{A}}^{Q_{B}}\left(m_{3 i} \cdot Q_{i}\right) \cdot d Q_{i}
$$

Where the coefficients indicate different items in reactive power generation costs provided by ith synchronous generator which are required to recommend in the market. These coefficients are explained as follows:

$\mathrm{a}_{0}$ : the price of availability $(\$)$

$\mathrm{m}_{1}$ : recommended price for exploitation in underexcited mode (absorbed reactive power) (\$/MVArh)

$\mathrm{m}_{2}$ : the recommended price of loss for exploiting in the second area (\$/MVArh)

As it is shown above, opportunity price is a function of reactive power output and, hence, the expected payment function of lost opportunity cost is a quadratic $\mathrm{Q}$ function.

$\mathrm{m}_{3}$ : the recommended lost opportunity price for exploitation in the second area is based on $Q_{A} \leq Q \leq$ $Q_{B}, \frac{(\$ M V a r-h)}{M V a r-h}$. According to equation (1), if a generator is accepted in in reactive power market, it will receive the availability price which is independent of its capacity. In this case, the compensator capacity is not considered in the reactive power market. However, in reality, the available capacity of the unit must be taken into account, since the availability of a big unit is doubtlessly of higher importance in terms of the availability of enough reactive storage in system and possessing a grid with desirable-voltage static security. For this matter, a bigger unit must be more financially compensated. So it is recommended to set the availability cost of the unit in the revised model proportionate to the reactive power capacity of the respective unit. Hence, the availability price item $\left(\mathrm{a}_{0}\right)$ must be based on \$/MVar rather than $\$$ in order to apply the previously-mentioned point. Beside this, in the revised model, each generator suggests two pricing items for availability: the availability component to absorb reactive power $\left(a_{o, i}^{-}\right)$based on $\$ / M V a r$, and availability component to generate reactive power $\left(a_{o, i}^{+}\right)$based on $\$$ MVar. After corrections, the revised expected payment function would be as follows:

$\mathrm{EPF}_{\mathrm{i}}=\mathrm{a}_{0, i}^{-} \cdot \mathrm{Q}_{\min , \mathrm{i}}+\mathrm{a}_{0, i}^{+} \cdot \mathrm{Q}_{\max , \mathrm{i}}+\int_{\mathrm{Q}_{\min }}^{0} \mathrm{~m}_{1 \mathrm{i}} \cdot d \mathrm{Q}_{\mathrm{i}}+\int_{\mathrm{Q}_{\text {base }}}^{\mathrm{Q}_{\mathrm{A}}} \mathrm{m}_{2 \mathrm{i}} \cdot \mathrm{d} \mathrm{Q}_{\mathrm{i}}+\int_{\mathrm{Q}_{\mathrm{A}}}^{\mathrm{Q}_{\mathrm{B}}}\left(\mathrm{m}_{3 \mathrm{i}} \cdot \mathrm{Q}_{\mathrm{i}}\right) \cdot \mathrm{d} \mathrm{Q}_{\mathrm{i}}$

In addition, since the amounts of $\mathrm{Q}_{\mathrm{B}}, \mathrm{Q}_{\mathrm{A}}$ and $\mathrm{Q}_{\mathrm{base}}$ are not equal for all units and each unit has its own amounts (which must be paid attention in integral intervals in equation (2) - the final revised payment function would be:

$\mathrm{EPF}_{\mathrm{i}}=\mathrm{a}_{0, i}^{-} \cdot \mathrm{Q}_{\min , \mathrm{i}}+\mathrm{a}_{0, i}^{+} \cdot \mathrm{Q}_{\max , \mathrm{i}}+\int_{\mathrm{Q}_{\min , \mathrm{i}}}^{0} \mathrm{~m}_{1 \mathrm{i}} \cdot \mathrm{d} \mathrm{Q}_{\mathrm{i}}+\int_{\mathrm{Q}_{\text {base }, \mathrm{i}}}^{\mathrm{Q}_{\mathrm{A}, \mathrm{i}}} \mathrm{m}_{2 \mathrm{i}} \cdot \mathrm{d} \mathrm{Q}_{\mathrm{i}}+\int_{\mathrm{Q}_{\mathrm{A}, \mathrm{i}}}^{\mathrm{Q}_{\mathrm{B}, \mathrm{i}}}\left(\mathrm{m}_{3 \mathrm{i}} \mathrm{Q}_{\mathrm{i}}\right) \cdot d \mathrm{~d}_{\mathrm{i}}$

Whose schematic curve is shown in figure 2. 


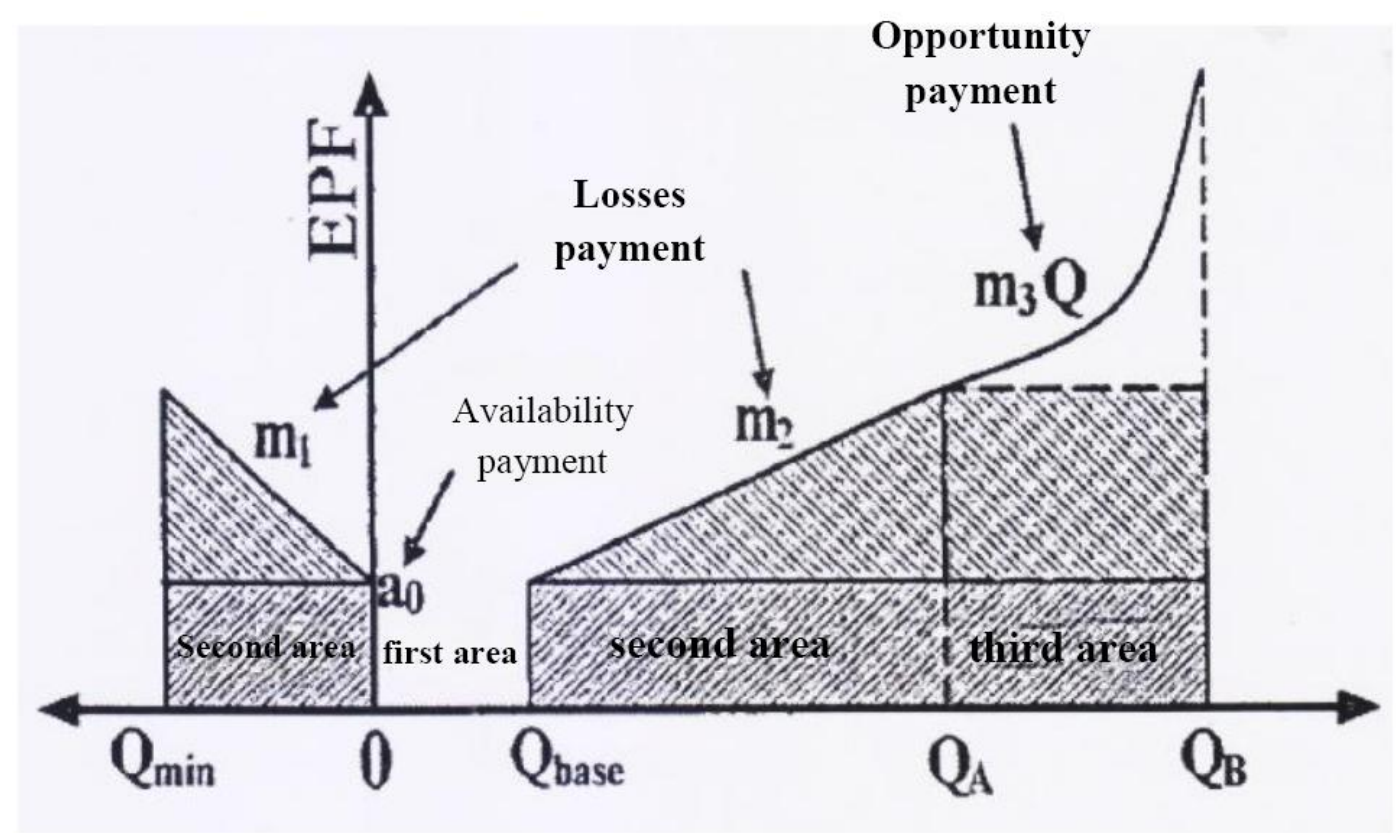

Figure2. Expected payment function (EPF) curve

The model target function is:

$T P F=\sum_{\mathrm{i} \in \text { gen }}\left(\rho_{0} \mathrm{~W}_{0, \mathrm{i}}-\rho_{1} \mathrm{~W}_{1, \mathrm{i}}\left(\mathrm{Q}_{\mathrm{i}}-\mathrm{Q}_{\text {min }, \mathrm{i}}\right)+\rho_{2} \mathrm{~W}_{2, \mathrm{i}}\left(\mathrm{Q}_{\mathrm{i}}-\mathrm{Q}_{\text {base }, \mathrm{i}}\right)+0.5 * \rho_{3} \mathrm{~W}_{3, \mathrm{i}}\left(\mathrm{Q}_{\mathrm{i}}^{2}-\mathrm{Q}_{\mathrm{A}, \mathrm{i}}^{2}\right)\right)$

Where $\rho_{0}, \rho_{1}, \rho_{2}$ and $\rho_{3}$ are market settlement prices for $\mathrm{a}_{0}, \mathrm{~m}_{1}, \mathrm{~m}_{2}$ and $\mathrm{m}_{3}$, respectively. $\mathrm{W}_{0}, \mathrm{~W}_{1}, \mathrm{~W}_{2}$ and $\mathrm{W}_{3}$ are binary variables in which $\mathrm{W}_{0}$ shows whether the unit is accepted in the market, and $\mathrm{W}_{1}$, $\mathrm{W}_{2}$ and $\mathrm{W}_{3}$ show performance in reactive power absorption area, reactive power generation area and lost opportunity area, respectively. The target function is the issue concerning optimization load distribution for reactive power market settlement and minimizing TPF in which the total sum of money paid to the unites in reactive power market is minimized. The market is based on uniform auction and the price of market settlement is determined for each of recommended pricing items. The revised TPF, based on revised expected payment function, is as follows:

$\mathrm{TPF}=\sum_{\mathrm{i} \in \operatorname{gen}}\left(\rho_{0}^{+} \mathrm{Q}_{\mathrm{g} \max , \mathrm{i}} \mathrm{W}_{0, \mathrm{i}}^{+}-\rho_{0}^{-} \mathrm{Q}_{\mathrm{g} \min , \mathrm{i}} \mathrm{W}_{0, \mathrm{i}}^{-}-\rho_{1} \mathrm{~W}_{1, \mathrm{i}} \mathrm{Q}_{\mathrm{i}}+\rho_{2} \mathrm{~W}_{2, \mathrm{i}}\left(\mathrm{Q}_{\mathrm{i}}-\mathrm{Q}_{\text {base }, i}\right)+0.5 *\right.$ $\rho 3 \mathrm{~W} 3, \mathrm{i}(\mathrm{Q} \mathrm{i} 2-\mathrm{QA}, \mathrm{i} 2)$

Where $W_{o, i}^{+}$and $W_{o, i}^{-}$are binary variables specified for reactive generation and absorption, respectively. Further, $\mathrm{W}_{1}, \mathrm{~W}_{2}$ and $\mathrm{W}_{3}$ are performance in reactive power absorption area, reactive power generation and lost opportunity area, respectively.

\subsection{Reactive Power Market Settlement}

To determine the amount of reactive power absorption or generation of each of generators participated in the reactive power market, optimization load distribution is used. The target function of this issue is the minimization of revised TPF which must be paid by the system independent exploiter to the units. Hence, the optimization load distribution is:

$\mathrm{TPF}=\sum_{\mathrm{i}=1}^{\mathrm{NB}} \sum_{\mathrm{u}=1}^{\mathrm{NU}}\left(\rho_{0}^{+} \mathrm{Q}_{\mathrm{G} \text { max }}^{\mathrm{i}, \mathrm{u}} \mathrm{W}_{0}^{+\mathrm{i}, \mathrm{u}}-\rho_{0}^{-} \mathrm{Q}_{\mathrm{G} \text { min }}^{\mathrm{i}, \mathrm{u}} \mathrm{W}_{0}^{-\mathrm{i}, \mathrm{u}}-\rho_{1} \mathrm{~W}_{1}^{\mathrm{i}, \mathrm{u}} \mathrm{Q}_{1 \mathrm{G}}^{\mathrm{i}, \mathrm{u}}+\rho_{2} \mathrm{~W}_{2}^{\mathrm{i}, \mathrm{u}}\left(\mathrm{Q}_{2}^{\mathrm{i}, \mathrm{u}}-\mathrm{Q}_{\mathrm{G} \text { base }}^{\mathrm{i}, \mathrm{u}}\right)+\right.$ $0.5 * \rho 3 \mathrm{~W} 3 \mathrm{i}, \mathrm{u}((\mathrm{Q} 3 \mathrm{Gi}, \mathrm{u}) 2-(\mathrm{QG}$ basei, u $) 2)$

(6)

Where NB is the number of grid nodes and Nui is the number of units connected to the ith node of the grid. Optimized load distribution consists of following equal and unequal limits:

\section{a) Load distribution limits}

$\sum_{u=1}^{N U_{i}} P_{G}^{\mathrm{i}, \mathrm{u}}-\mathrm{P}_{\mathrm{Di}}=\sum_{\mathrm{j}=1}^{\mathrm{NB}} \mathrm{V}_{\mathrm{i}} \mathrm{V}_{\mathrm{j}} \mathrm{Y}_{\mathrm{ij}} \cos \left(\delta_{\mathrm{i}}-\delta_{\mathrm{j}}-\theta_{\mathrm{ij}}\right)$
$\sum_{u=1}^{N U_{\mathrm{i}}} \mathrm{Q}_{\mathrm{G}}^{\mathrm{i}, \mathrm{u}}-\mathrm{Q}_{\mathrm{Di}}=\sum_{\mathrm{j}=1}^{\mathrm{NB}} \mathrm{V}_{\mathrm{i}} \mathrm{V}_{\mathrm{j}} \mathrm{Y}_{\mathrm{ij}} \sin \left(\delta_{\mathrm{i}}-\delta_{\mathrm{j}}-\theta_{\mathrm{ij}}\right)$ 
$\sum_{u=1}^{\mathrm{NU}} \widehat{\mathrm{P}}_{\mathrm{G}}^{\mathrm{i}, \mathrm{u}}-\widehat{\mathrm{P}}_{\mathrm{Di}}=\sum_{\mathrm{j}=1}^{\mathrm{NB}} \widehat{\mathrm{V}}_{\mathrm{i}} \widehat{\mathrm{V}}_{\mathrm{j}} \mathrm{Y}_{\mathrm{ij}} \cos \left(\widehat{\delta}_{\mathrm{i}}-\widehat{\delta}_{\mathrm{j}}-\theta_{\mathrm{ij}}\right)$

$\sum_{u=1}^{\mathrm{NU}} \widehat{\mathrm{Q}}_{\mathrm{G}}^{\mathrm{i}, \mathrm{u}}-\widehat{\mathrm{Q}}_{\mathrm{Di}}=\sum_{\mathrm{j}=1}^{\mathrm{NB}} \widehat{\mathrm{V}}_{\mathrm{i}} \widehat{\mathrm{V}}_{\mathrm{j}} \mathrm{Y}_{\mathrm{ij}} \sin \left(\widehat{\delta}_{\mathrm{i}}-\widehat{\delta}_{\mathrm{j}}-\theta_{\mathrm{ij}}\right)$

Where $\left({ }^{\wedge}\right)$ indicates the amount of electric quantities in the Security Loading Point (SLP) of the grid.

b) limits relating to determination of performance area of each unit

$\mathrm{W}_{0}^{+\mathrm{i}, \mathrm{u}}, \mathrm{W}_{0}^{-\mathrm{i}, \mathrm{u}}, \mathrm{W}_{1}^{\mathrm{i}, \mathrm{u}}, \mathrm{W}_{2}^{\mathrm{i}, \mathrm{u}}, \mathrm{W}_{3}^{\mathrm{i}, \mathrm{u}} \in\{0,1\}$

$\mathrm{Q}_{\mathrm{G}}^{\mathrm{i}, \mathrm{u}}=\mathrm{Q}_{1 \mathrm{G}}^{\mathrm{i}, \mathrm{u}}+\mathrm{Q}_{2 \mathrm{G}}^{\mathrm{i}, \mathrm{u}}+\mathrm{Q}_{3 \mathrm{G}}^{\mathrm{i}, \mathrm{u}}$

$\mathrm{W}_{1}^{\mathrm{i}, \mathrm{u}} \cdot \mathrm{Q}_{\min \mathrm{G}}^{\mathrm{i}, \mathrm{u}} \leq \mathrm{Q}_{1 \mathrm{G}}^{\mathrm{i}, \mathrm{u}} \leq 0$

$\mathrm{W}_{2}^{\mathrm{i}, \mathrm{u}} \cdot \mathrm{Q}_{\text {base G }}^{\mathrm{i}, \mathrm{u}} \leq \mathrm{Q}_{2 \mathrm{G}}^{\mathrm{i}, \mathrm{u}} \leq \mathrm{W}_{2}^{\mathrm{i}, \mathrm{u}} \cdot \mathrm{Q}_{\mathrm{A} G}^{\mathrm{i}, \mathrm{u}}$

$\mathrm{W}_{3}^{\mathrm{i}, \mathrm{u}} \cdot \mathrm{Q}_{\mathrm{A} G}^{\mathrm{i}, \mathrm{u}} \leq \mathrm{Q}_{3 \mathrm{G}}^{\mathrm{i}, \mathrm{u}} \leq \mathrm{W}_{3}^{\mathrm{i}, \mathrm{u}} \cdot \mathrm{Q}_{\mathrm{B} G}^{\mathrm{i}, \mathrm{u}}$

$\mathrm{W}_{1}^{\mathrm{i}, \mathrm{u}}+\mathrm{W}_{2}^{\mathrm{i}, \mathrm{u}}+\mathrm{W}_{3}^{\mathrm{i}, \mathrm{u}} \leq 1$

$\mathrm{W}_{0}^{-\mathrm{i}, \mathrm{u}}+\mathrm{W}_{2}^{\mathrm{i}, \mathrm{u}}+\mathrm{W}_{3}^{\mathrm{i}, \mathrm{u}} \leq 1$

$\mathrm{W}_{0}^{+\mathrm{i}, \mathrm{u}}+\mathrm{W}_{1}^{\mathrm{i}, \mathrm{u}} \leq 1$

$\mathrm{W}_{0}^{-\mathrm{i}, \mathrm{u}}+\mathrm{W}_{0}^{+\mathrm{i}, \mathrm{u}} \leq 1$

$\mathrm{W}_{1}^{\mathrm{i}, \mathrm{u}}+\mathrm{W}_{2}^{\mathrm{i}, \mathrm{u}}+\mathrm{W}_{3}^{\mathrm{i}, \mathrm{u}} \leq \mathrm{W}_{0}^{-\mathrm{i}, \mathrm{u}}+\mathrm{W}_{0}^{+\mathrm{i}, \mathrm{u}}$

$\mathrm{Q}_{\mathrm{G}}^{\mathrm{i}, \mathrm{u}} \leq \sqrt{\left(\mathrm{V}_{\mathrm{t}}^{\mathrm{i}, \mathrm{u}} \cdot \mathrm{I}_{\mathrm{t}}^{\mathrm{i}, \mathrm{u}}\right)^{2}-\left(\mathrm{P}_{\mathrm{G}}^{\mathrm{i}, \mathrm{u}}\right)^{2}}$

$Q_{G}^{i, u} \leq \sqrt{\left(\frac{v_{t}^{i, u} \cdot E_{a, f}^{i, u}}{X_{s}^{i, u}}\right)^{2}-\left(P_{G}^{i, u}\right)^{2}}-\frac{\left(V_{t}^{i, u}\right)^{2}}{X_{s}^{i, u}}$

Where $W_{0}^{-i, u}$ is the binary variable for $\mathrm{u}^{\text {th }}$ generator performance connected to ith bus under the state of absorbing reactive power, and $W_{0}^{+i, u}$ is regarded as the respective generator performance under the state of generating reactive power. The equation (17) inhibits the performance of a unit selected for absorbing reactive power in the market $\left(W_{0}^{-i, u}=1\right)$, and in the reactive power generation area (second and third areas) $\left(W_{3}^{i, u}=1\right.$ or $\left.W_{2}^{i, u}=1\right)$. Similarly, the equation (18) inhibits the performance of a unit selected to absorb the reactive power generation in market $\left(W_{0}^{+i, u}=1\right)$ in the reactive power generation area $\left(W_{1}^{i, u}=1\right)$. If a unit is not selected in reactive power market, and if is selected and compensate the reactive power in the second or third area, then the equation (20) would be $(0=0)$ and $(1=1)$, respectively. However, if a unit is selected in reactive power market but does not compensate reactive power, instead stores the reactive power in the grid, then the equation (20) would be $(0 \leq 1)$. Equations $(21)$ and (22) indicate that grid working point must be within the synchronous generator capability curve.

c) Limits relating to determining market settlement price for each of reactive power market pricing items

$W_{0}^{-i, u} \cdot a_{0}^{-i, u} \leq \rho_{0}^{-}$

$\mathrm{W}_{0}^{+\mathrm{i}, \mathrm{u}} \cdot \mathrm{a}_{0}^{+\mathrm{i}, \mathrm{u}} \leq \rho_{0}^{+}$

$\mathrm{W}_{1}^{\mathrm{i}, \mathrm{u}} \cdot \mathrm{m}_{1}^{\mathrm{i}, \mathrm{u}} \leq \rho_{1}(25)$

$\left(W_{2}^{\mathrm{i}, \mathrm{u}}+\mathrm{W}_{3}^{\mathrm{i}, \mathrm{u}}\right) \cdot \mathrm{m}_{2}^{\mathrm{i}, \mathrm{u}} \leq \rho_{2}$

$\mathrm{W}_{3}^{\mathrm{i}, \mathrm{u}} \cdot \mathrm{m}_{3}^{\mathrm{i}, \mathrm{u}} \leq \rho_{3}$

Where $\rho_{0}^{-}$is the uniform auction price available for absorbing reactive power, and $\rho_{0}^{+}$is the
availability price for generating reactive power. $\rho_{1}$ is the market settlement price of loss factor under the status of reactive power absorption, $\rho_{2}$ is the market settlement price of loss factor under the status of reactive power generation, and $\rho_{3}$ is the market settlement price of lost opportunity cost. 
d) Limits relating to security (nodes voltage and lines current)

$$
\begin{aligned}
& \mathrm{S}_{\mathrm{b}, \mathrm{i}} \leq \mathrm{S}_{\mathrm{b}, \mathrm{i}}^{\max } \\
& \mathrm{V}_{\mathrm{k}}^{\min } \leq \mathrm{V}_{\mathrm{k}} \leq \mathrm{V}_{\mathrm{k}}^{\max } \\
& \mathrm{VSM} \geq \mathrm{VSM}^{\text {spec }} \\
& \widehat{\mathrm{S}}_{\mathrm{b}, \mathrm{i}} \leq \mathrm{S}_{\mathrm{b}, \mathrm{i}}^{\max } \\
& \mathrm{V}_{\mathrm{k}}^{\min } \leq \widehat{\mathrm{V}}_{\mathrm{k}} \leq \mathrm{V}_{\mathrm{k}}^{\max } \\
& \lambda \geq \lambda_{\min } \\
& \widehat{\mathrm{P}}_{\mathrm{G}}^{\mathrm{i}, \mathrm{u}}=\left(1+\lambda+\mathrm{k}_{\mathrm{G}}\right) \mathrm{P}_{\mathrm{G}}^{\mathrm{i}, \mathrm{u}} \\
& \widehat{\mathrm{P}}_{\mathrm{Di}}=(1+\lambda) \mathrm{P}_{\mathrm{Di}} \\
& \widehat{\mathrm{Q}}_{\mathrm{Di}}=(1+\lambda) \mathrm{Q}_{\mathrm{Di}}
\end{aligned}
$$

Equations (28) and (29) indicate security limits in the grid security loading point, equation (30) shows the limit of voltage stability margin (meaning equations 33 to 36), equations (31) and (32) indicate the voltage stability limit and the equations (28) to (33) explain security limits at current running point.

\section{Modeling the UnCertainty of Wind Powered Generation}

The main objective in this part is to model the accidental behavior of wind powered generation (WPG). Firstly a model of time series based on Limited Autoregressive Integrated Moving Average (LAIMV) method is introduced and explained which is used for modeling WPG accidental behavior. The important point in using this method is that to reach precise results and achieve a more actual model, mutual correlation between wind farms located in neighboring sites is applied in modeling wind power by means of LARIMA.

\subsection{ARIMA Family Models}

Different models of this family (namely ARIMA (p,d,q)) are used for modeling the accidental procedure of $\mathrm{Y}(\mathrm{t})$ [12]. The total relationship between these family members is shown in equation (37). The amount of $\varphi_{i}$ relates to the coefficient of autoregressive (AR), $\theta_{i}$ indicates the moving average (MA) coefficient, and a(t) is white Gaussian distribution function including a Gaussian distribution with zero average and $\sigma_{\alpha}^{2}$ variance. The $\theta_{0}$ parameter introduces the certain behavior changes of the respective process.

$$
\left(1-\sum_{\mathrm{i}=1}^{\mathrm{P}} \varphi_{\mathrm{i}} \mathrm{B}^{\mathrm{i}}\right)(1-\mathrm{B})^{\mathrm{d}} \mathrm{Y}(\mathrm{t})=\theta_{0}+\left(1-\sum_{\mathrm{i}=1}^{\mathrm{q}} \theta_{\mathrm{i}} \mathrm{B}^{\mathrm{i}}\right) \mathrm{a}(\mathrm{t})
$$

\subsection{Wind Power Time Series' Statistical Analysis}

The statistical information used in this source for time series of wind power were obtained from a wind farm in Nysted city in Denmark whose generative power in Lolland Falster distribution network was used. The generative capacity of the whole farm was $165 \mathrm{Mw}$ consisting of 72 wind turbines performing at uniform speed (with the capacity of $2.3 \mathrm{Mw}$ for each turbine). The time series changes curve of wind power along with its behavior in first 10 days of January in 2010 for this wind farm are shown in figure 3

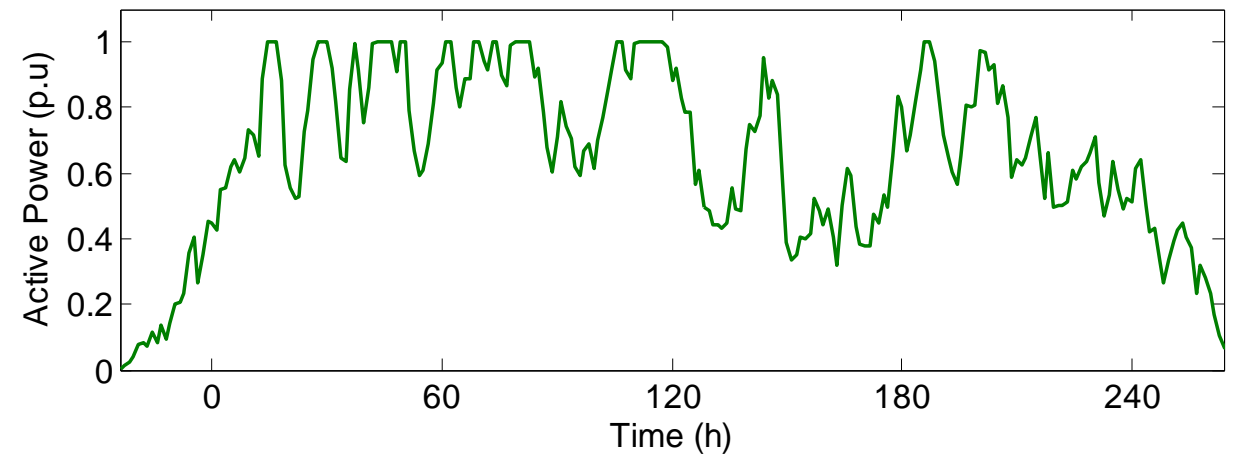

Figure3. Measuring the amount of output power in 10 days 


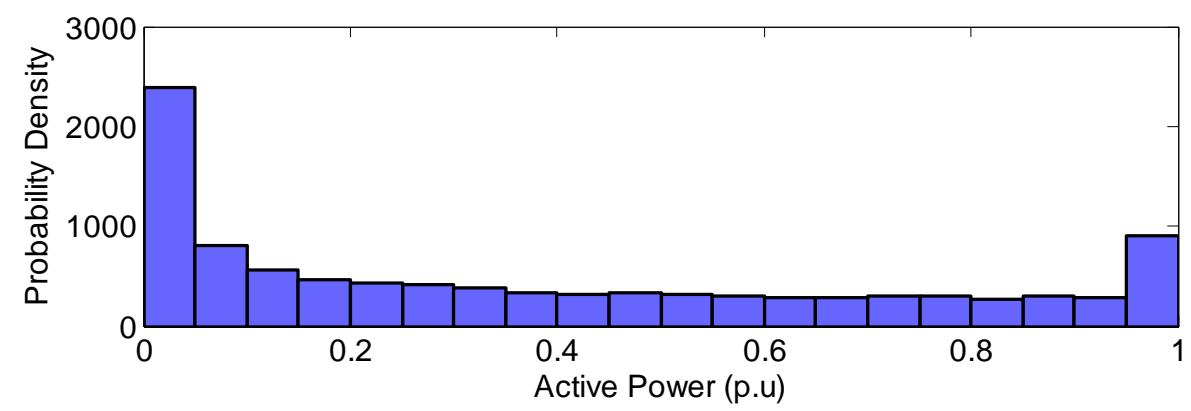

Figure4. The probabilistic distribution function of the wind farm's output power

\subsection{The Implemented Model for Modeling the Accidental Behavior of Wind Power}

ARIMA $(0,1,1)$ model in this study is used for time series of wind power. The linear ARMA model is shown in equation (38):

$(1-\mathrm{B}) \mathrm{I}_{0}(\mathrm{t})=\left(1-\theta_{1} \mathrm{~B}\right) \mathrm{a}(\mathrm{t})$

$\mathrm{Y}(\mathrm{t})=\mathrm{I}_{0}^{2}(\mathrm{t}), \quad$ for $\mathrm{t}=1, \ldots, \mathrm{N}$

In discussing around modeling wind behavior, the exploited wind power is subject to generation threshold due to existent physical limitations of wind farms. This holds while neither ARMA nor ARIMA method can apply the maximum limit of power in wind behavior modeling. In this regard, no doubt that ARMA and ARIMA standard models cannot be used directly for accident processes with limits. Hence, regarding the structural limitations of wind turbines, wind power exploitation involves upmost and bottommost limits in generative power. The polynomial equation (39) can be used to calculate wind power where $I_{\max }$ and $I_{\min }$ show maximum and minimum amount of square wind output power, respectively. In a simulation for calculating wind time series, the restrictor and block relating to high wind power limit application in feedback shifter loop is set backward which is shown by LARIMA.

$\mathrm{I}(\mathrm{t})=\left\{\begin{array}{lr}\mathrm{I}_{\max }, & \mathrm{I}_{0}(\mathrm{t})>\mathrm{I}_{\max } \\ \mathrm{I}_{0}(\mathrm{t}), & \mathrm{I}_{\min }<\mathrm{I}_{0}(\mathrm{t})<\mathrm{I}_{\max } \\ \mathrm{I}_{\text {min }}, & \mathrm{I}_{0}(\mathrm{t})<\mathrm{I}_{\text {min }}\end{array}\right.$

Modeling correlation in calculating wind power time series is categorized into two main categories: cross-correlation and auto-correlation. Autocorrelation relates to logical changes of wind behavior and its relationship with wind power of each wind farm in different hours. On the other hand, crosscorrelation is the correlation between wind power of different farms which is used in a region with similar geographical location. Put simply, autocorrelation must be used to calculate wind power series of a single wind farm and both types of correlations must be used for several wind farms through applying specific coefficients in simulation.

To simulate time series of farms considered in the sample system and, also, modeling the generative power of two parts of the wind farm, multivariate LARIMA $(0,1,1)$ would be used. Since two areas are assumed in the considering grid for simulation, the calculations relating to time series of total power of these farms need two-variable LARIMA $(0,1,1)$ regarding both cross- and autocorrelations. The formulas of this model (40-44) are implementable whose total diagram block is shown in figure 5. The two-variable LARIMA model consists different parts including collector, restrictor, power shift, autocorrelation and cross-correlation. The structure of cross-correlation includes two parts: 1) two-variable Gaussian white noise with $\sum \alpha$ covariance matrix, and 2) mutual relationship between two variables of white noise $\operatorname{by} \theta_{21}$ and $\theta_{12}$ parameters. Autocorrelation is applied to the model by $\theta_{22}$ and $\theta_{11}$ parameters.

$\left[\begin{array}{l}\mathrm{Z}_{1}(\mathrm{t}) \\ \mathrm{Z}_{2}(\mathrm{t})\end{array}\right]=\left[\begin{array}{l}\theta_{0.1} \\ \theta_{0,2}\end{array}\right]+\left\{\left[\begin{array}{ll}1 & 0 \\ 0 & 1\end{array}\right]-\left[\begin{array}{ll}\theta_{11} & \theta_{12} \\ \theta_{21} & \theta_{22}\end{array}\right] \mathrm{B}\right\} \times\left[\begin{array}{l}\mathrm{a}_{1}(\mathrm{t}) \\ \mathrm{a}_{2}(\mathrm{t})\end{array}\right]$

$\left[\begin{array}{l}\mathrm{Z}_{1}(\mathrm{t}) \\ \mathrm{Z}_{2}(\mathrm{t})\end{array}\right]=\left[\begin{array}{l}\mathrm{I}_{0.1}(\mathrm{t})-\mathrm{I}_{1}(\mathrm{t}-1) \\ \mathrm{I}_{0,2}(\mathrm{t})-\mathrm{I}_{2}(\mathrm{t}-1)\end{array}\right]$ 


$$
\begin{aligned}
& I_{1}(\mathrm{t})=\left\{\begin{array}{lr}
\mathrm{I}_{\max }, & \mathrm{I}_{0.1}(\mathrm{t})>\mathrm{I}_{\max } \\
\mathrm{I}_{0,1}(\mathrm{t}), & \mathrm{I}_{\text {min }}<\mathrm{I}_{0,1}(\mathrm{t})<\mathrm{I}_{\max } \\
\mathrm{I}_{\text {min }}, & \mathrm{I}_{0,1}(\mathrm{t})<\mathrm{I}_{\min }
\end{array}\right. \\
& \mathrm{I}_{2}(\mathrm{t})=\left\{\begin{array}{lc}
\mathrm{I}_{\max }, & \mathrm{I}_{0.2}(\mathrm{t})>\mathrm{I}_{\max } \\
\mathrm{I}_{0,2}(\mathrm{t}), & \mathrm{I}_{\min }<\mathrm{I}_{0,2}(\mathrm{t})<\mathrm{I}_{\max } \\
\mathrm{I}_{\min }, & \mathrm{I}_{0,2}(\mathrm{t})<\mathrm{I}_{\min }
\end{array}\right. \\
& {\left[\begin{array}{l}
\mathrm{Y}_{1}(\mathrm{t}) \\
\mathrm{Y}_{2}(\mathrm{t})
\end{array}\right]=\left[\begin{array}{l}
\mathrm{I}_{1}^{2}(\mathrm{t}) \\
\mathrm{I}_{2}^{2}(\mathrm{t})
\end{array}\right]}
\end{aligned}
$$

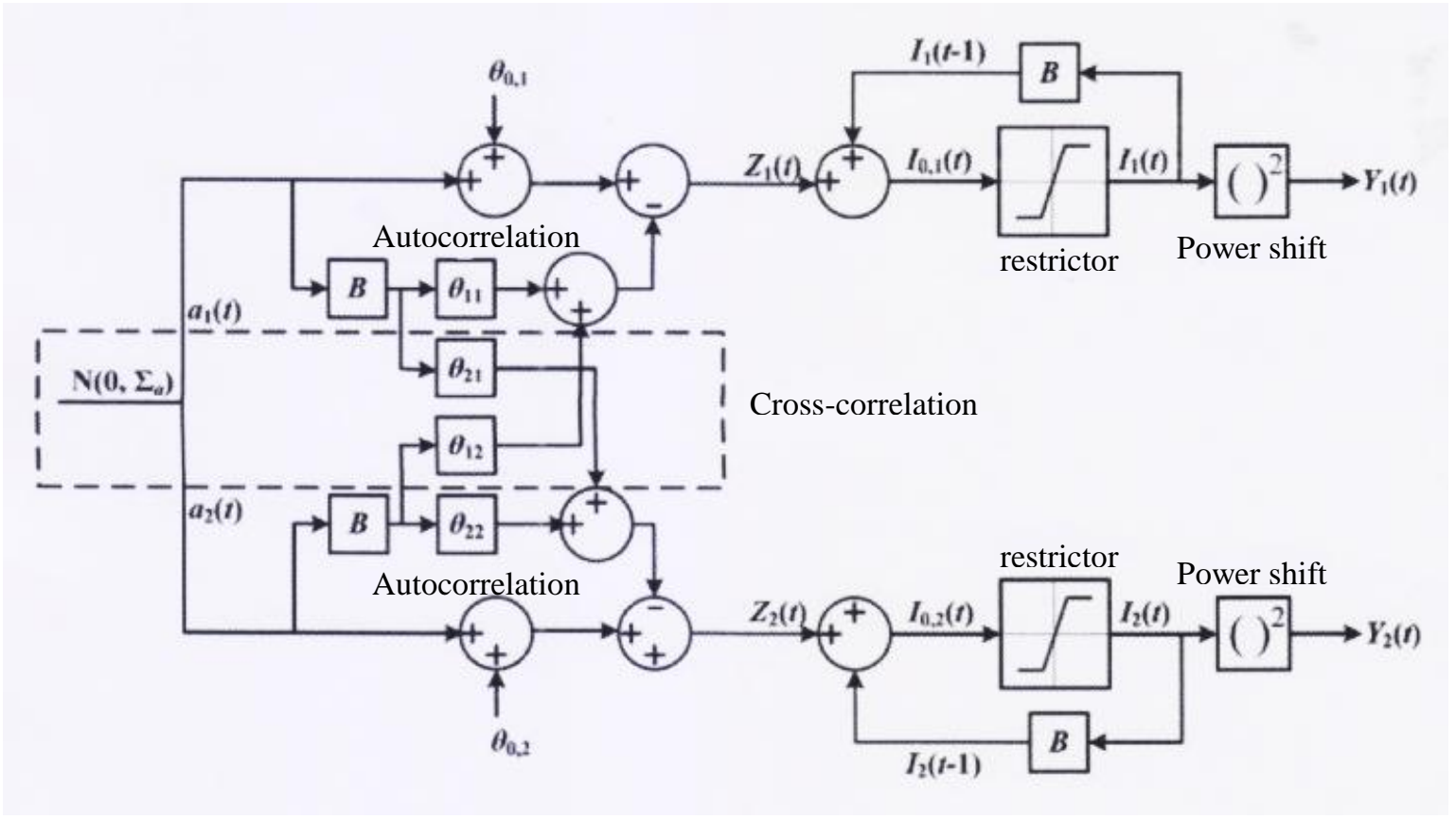

Figure5. 2-variable LARIMA $(0,1,1)$ diagram block

Figure 6 shows wind power series changes for two areas in a 2-week period in which cross- and autocorrelation are clearly indicated.

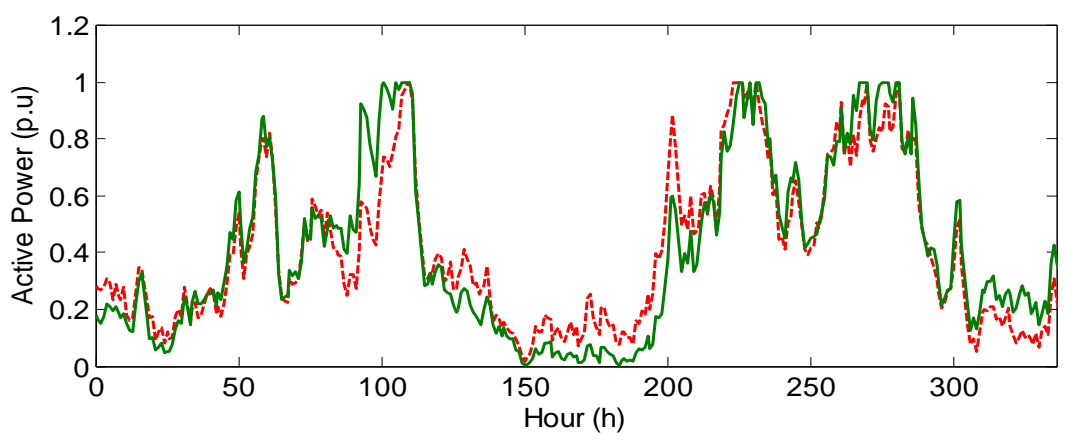

Figure6. The simulated amounts of wind turbine output power for 2 areas

\section{ACCidental Modeling of CONSUMing LoAd OF Distribution Network}

The hour load series of a network can be indicated in form of a Gaussian accidental variable. A Gaussian variable is only shown with mean and standard variance parameters. If hour load amounts are subtracted from the mean of that hour and then normalized, load changes series will be reached from mean status which could be simulated by AR accidental model. In many articles, normal distribution function is used for creating this error variable where there would be no enough correlation between consecutive samples. In this article, however, AR(12) model is used for creating load changes series where parameters are calculated through real load changes and then added to the model [3]. Finally, this accidental variable is normalized to the standard variance of major load and then added to the hour load mean. 
The hourly measured consuming active power relates to the year 2009. As is observed, the amount of load in weekends and middle days of the week are significantly different. Hence, to model the load, it is divided into 4 categories: summer-middle of the week, summer-weekend, winter-middle of the week, and winter-weekend. Modeling is performed separately for each category.

Autocorrelation coefficients of measured series relating to consuming load are shown in figure 7. As is clear, they have greater amounts in 24 hours and during a week.

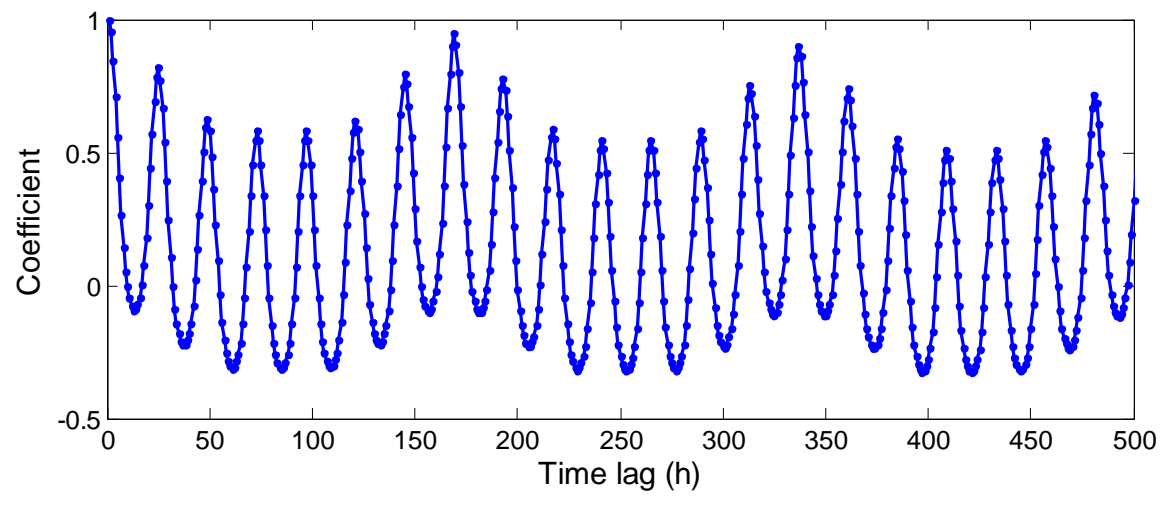

Figure7. Autocorrelation coefficients of consuming load series

To assess this issue in order to see whether hour load series can be modeled by a normal distribution function, Probability Density Function (PDF) corresponding to time series of load amounts at 1 and 7 o'clock of a working day are shown in figure 8. With keeping load amounts and corresponding probability with them in mind, it is clear that at 1 o'clock there is a little load and, conversely, 7 o'clock is one of peak load hours in the network.

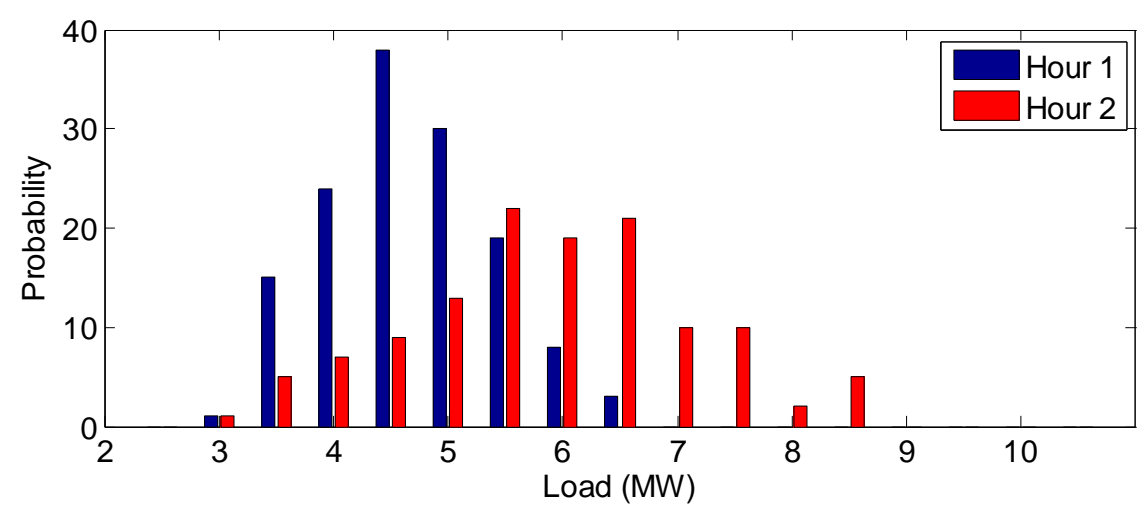

Figure8: Histogram function of 1 and 7 hours in a summer working day

Gaussian accidental variables are determined only through mean and standard variance. Periodic mean and standard variance relating to a summer working day are shown in figure 9 . Series of a summer working day load after being normalized is shown in figure 10. Now, this transmitted series must be modeled by AR model followed by combination with mean and standard variance to reach the favorable load series.

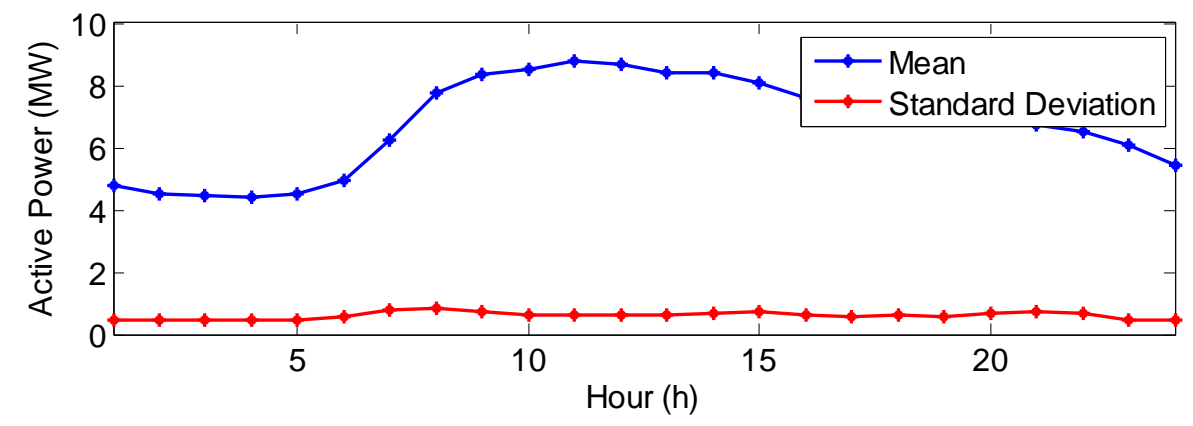

Figure9. Load mean and standard variance of a summer working day 
Reactive Power Market-Management Considering Uncertainties of Load and Power of Wind Powerhouses

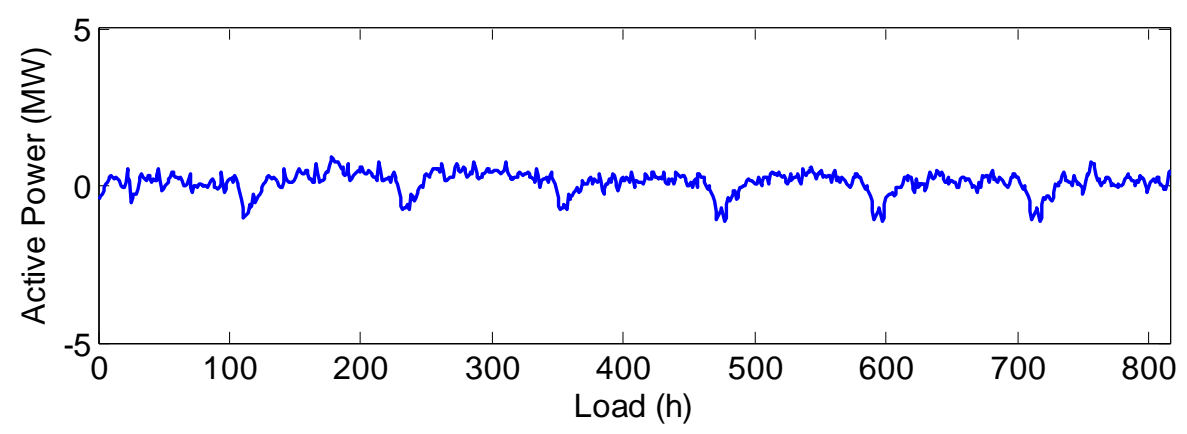

Figure10. Normalized load time series of a summer working day

Assuming that $\mathrm{Y}(\mathrm{t})$ equals to several accidental processes, the equation of AR model at $\mathrm{p}^{\text {th }}$ level of this process would be:

$\mathrm{Y}(\mathrm{t})=\mathrm{a}(\mathrm{t})+\sum_{\mathrm{i}=1}^{\mathrm{p}} \varphi_{\mathrm{i}} \mathrm{Y}(\mathrm{t}-\mathrm{i})$

To generate the grid load series, first, it is needed to subtract mean amount from the hour load amounts and then normalize them. Afterwards, these amounts are used to reach AR(12) model's parameters. In the following, the introduced model is used for generating normalized change series of consuming load. And finally, these amounts are changed to consuming load by adding mean and standard variance. The modeled load is shown in figure 11 .

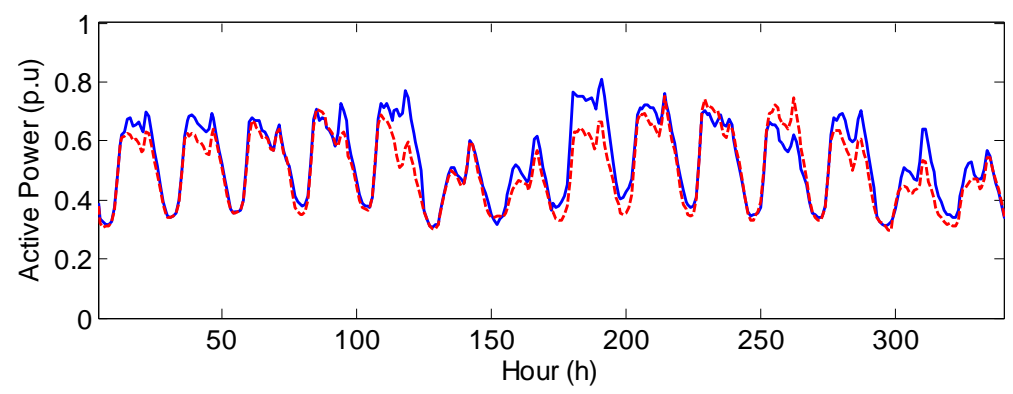

Figure11. The modeled load during 2 weeks

\section{SAMPLE GRID AND ITS ASSUMPTIONS}

As pointed out before, this article aims at simulating in order to analyze short-term market of power system reactive power so that the two major issues, uncertainty relating to generative power of wind farms and the change of grid load behavior are taken into account in the market model. To simulate and considering the above-mentioned issue, the 24-bus RTS system, which is analyzed in certaintyrelated articles, is regarded as the sample system on which the simulation of short-term market settle model of reactive power is applied, as well as implementing wind power uncertainties and grid consuming load. According to sources, 24-bus RTS grid consists of 33 traditional power generative units (steam units) which are capable of generating active and reactive power needed by the network. The information relating to maximum and minimum capacity of reactive/active powers generation are shown in table 1 , as well as the coefficients of reactive power costs.

Table1. The recommended price parameters for reactive power procurement and the capability of generative units

\begin{tabular}{|c|c|c|c|c|c|c|c|c|}
\hline $\begin{array}{c}\text { Gen } \\
\text { Units }\end{array}$ & $\mathrm{a}_{0}$ & $\mathrm{~m}_{1}$ & $\mathrm{~m}_{2}$ & $\mathrm{~m}_{3}$ & $\mathrm{P}_{\max }$ & $\mathrm{P}_{\min }$ & $\mathrm{Q}_{\max }$ & $\mathrm{Q}_{\min }$ \\
\hline 1 & $0 / 96$ & $0 / 86$ & $0 / 86$ & $0 / 46$ & 20 & 16 & 10 & 0 \\
\hline 2 & $0 / 94$ & $0 / 82$ & $0 / 82$ & $0 / 45$ & 20 & 16 & 10 & 0 \\
\hline 3 & $0 / 85$ & $0 / 79$ & $0 / 79$ & $0 / 39$ & 76 & $15 / 2$ & 30 & -25 \\
\hline 4 & $0 / 83$ & $0 / 82$ & $0 / 82$ & $0 / 4$ & 76 & $15 / 2$ & 30 & -25 \\
\hline 5 & $0 / 5$ & $0 / 54$ & $0 / 54$ & $0 / 28$ & 20 & 16 & 10 & 0 \\
\hline 6 & $0 / 42$ & $0 / 42$ & $0 / 42$ & $0 / 35$ & 20 & 16 & 10 & 0 \\
\hline 7 & $0 / 69$ & $0 / 68$ & $0 / 68$ & $0 / 39$ & 76 & $15 / 2$ & 30 & -25 \\
\hline 8 & $0 / 65$ & $0 / 62$ & $0 / 62$ & $0 / 37$ & 76 & $15 / 2$ & 30 & -25 \\
\hline
\end{tabular}


Reactive Power Market-Management Considering Uncertainties of Load and Power of Wind Powerhouses

\begin{tabular}{|c|c|c|c|c|c|c|c|c|}
\hline 9 & $0 / 75$ & $0 / 61$ & $0 / 61$ & $0 / 43$ & 100 & 25 & 60 & 0 \\
\hline 10 & $0 / 8$ & $0 / 75$ & $0 / 75$ & $0 / 36$ & 100 & 25 & 60 & 0 \\
\hline 11 & $0 / 7$ & $0 / 65$ & $0 / 65$ & $0 / 32$ & 100 & 25 & 60 & 0 \\
\hline 12 & $0 / 68$ & $0 / 5$ & $0 / 5$ & $0 / 31$ & 197 & 69 & 80 & 0 \\
\hline 13 & $0 / 7$ & $0 / 54$ & $0 / 54$ & $0 / 39$ & 197 & 69 & 80 & 0 \\
\hline 14 & $0 / 75$ & $0 / 6$ & $0 / 6$ & $0 / 5$ & 197 & 69 & 80 & 0 \\
\hline 15 & $0 / 94$ & $0 / 81$ & $0 / 81$ & 0 & 0 & 0 & 200 & -50 \\
\hline 16 & $0 / 65$ & $0 / 6$ & $0 / 6$ & $0 / 3$ & 12 & $2 / 4$ & 6 & 0 \\
\hline 17 & $0 / 5$ & $0 / 58$ & $0 / 58$ & $0 / 25$ & 12 & $2 / 4$ & 6 & 0 \\
\hline 18 & $0 / 6$ & $0 / 73$ & $0 / 73$ & $0 / 38$ & 12 & $2 / 4$ & 6 & 0 \\
\hline 19 & $0 / 55$ & $0 / 61$ & $0 / 61$ & $0 / 27$ & 12 & $2 / 4$ & 6 & 0 \\
\hline 20 & $0 / 52$ & $0 / 5$ & $0 / 5$ & $0 / 26$ & 12 & $2 / 4$ & 6 & 0 \\
\hline 21 & $0 / 51$ & $0 / 51$ & $0 / 51$ & $0 / 27$ & 155 & $54 / 3$ & 80 & -50 \\
\hline 22 & $0 / 5$ & $0 / 5$ & $0 / 5$ & $0 / 3$ & 155 & $54 / 3$ & 80 & -50 \\
\hline 23 & $0 / 9$ & $0 / 85$ & $0 / 85$ & $0 / 48$ & 400 & 100 & 200 & -50 \\
\hline 24 & $0 / 8$ & $0 / 75$ & $0 / 75$ & $0 / 41$ & 400 & 100 & 200 & -50 \\
\hline 25 & $0 / 42$ & $0 / 42$ & $0 / 42$ & $0 / 17$ & 50 & 10 & 16 & -10 \\
\hline 26 & $0 / 5$ & $0 / 48$ & $0 / 48$ & $0 / 2$ & 50 & 10 & 16 & -10 \\
\hline 27 & $0 / 45$ & $0 / 42$ & $0 / 42$ & $0 / 38$ & 50 & 10 & 16 & -10 \\
\hline 28 & $0 / 48$ & $0 / 44$ & $0 / 44$ & $0 / 35$ & 50 & 10 & 16 & -10 \\
\hline 29 & $0 / 49$ & $0 / 45$ & $0 / 45$ & $0 / 33$ & 50 & 10 & 16 & -10 \\
\hline 30 & $0 / 55$ & $0 / 46$ & $0 / 46$ & $0 / 32$ & 50 & 10 & 16 & -10 \\
\hline 31 & $0 / 9$ & $0 / 85$ & $0 / 85$ & $0 / 48$ & 155 & $54 / 3$ & 80 & -50 \\
\hline 32 & $0 / 95$ & $0 / 89$ & $0 / 89$ & $0 / 55$ & 155 & $54 / 3$ & 80 & -50 \\
\hline 33 & $0 / 86$ & $0 / 8$ & $0 / 8$ & $0 / 45$ & 350 & 140 & 150 & -25 \\
\hline
\end{tabular}

The applied changes in this sample grid, compared to what stated in sources, relate to using 2 windturbine units inside this power networks in $8^{\text {th }}$ and $18^{\text {th }}$ buses. The configuration of this sample grid is shown in figure 12. The rest of primary information relating to the components of this grid is taken from standard 24-bus RTS system. One of the points of importance in simulating uncertainty relating to wind power generation is the issue of correlation among selected areas for two wind farms, and applying their coefficients in ARIMA model plan. The issue of wind power generation correlation and the utilized coefficients in simulation is, to some extents, equal to relationship and dependence of environment and the weather similarity of different areas in a power network which must be considered in planning. For this matter, due to the closeness of the above areas $\left(8^{\text {th }}\right.$ and $18^{\text {th }}$ buses $)$, the cross-correlation among WT units used in these areas is the important issue in simulating and calculating wind power series which has been taken into full consideration.

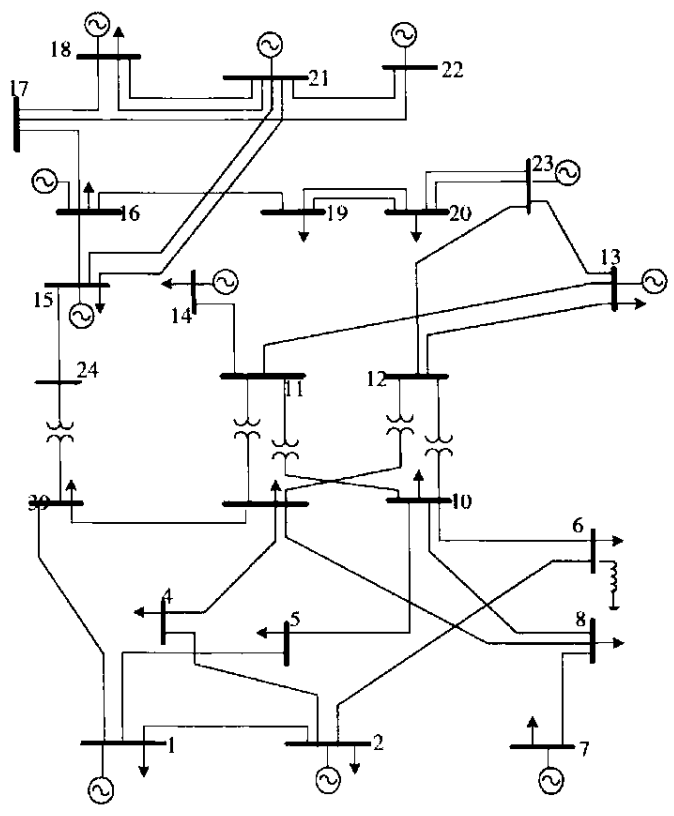

Figure12. The 24-bus RTS network

International Journal of Research Studies in Electrical and Electronics Engineering (IJRSEEE) Page | 45 
Reactive Power Market-Management Considering Uncertainties of Load and Power of Wind Powerhouses

The wind farms used in $8^{\text {th }}$ and $10^{\text {th }}$ buses each contains maximum generation capacity of $30 \mathrm{MW}$. The requested load from sample network is located in all 24 buses. The maximum consuming load of the whole network for a standard 24-bus RTS network is equal to 2850 MW. Full autocorrelation among load changes in each of areas, and strong cross-correlation among load changes in different areas of the sample network are of assumptions considered in generating network load accidental series. The issue of cross-correlation among different areas' load is, for some reasons, similar to common environmental features like temperature and weather conditions of the respective areas regarding creating network load series. The model of consuming load and its changes are simulated in of AR method.

The data relating to power generation of each of wind farms, as well as consuming load of the whole network, in 5 scenarios within a 5-hour time period for each is simulated and shown in tables 2-4.

Table2. Scenarios of generative power of wind farm WF1 (MW) for a 5-hour time horizon

\begin{tabular}{|c|c|c|c|c|c|}
\hline $\begin{array}{c}\text { scenario } \\
\text { time horizon }\end{array}$ & 1 & 2 & 3 & 4 & 5 \\
\hline first hour & $28 / 75822$ & $23 / 3223$ & $22 / 22299$ & $21 / 28333$ & $18 / 66151$ \\
\hline second hour & $19 / 18854$ & $26 / 61316$ & $23 / 58145$ & $18 / 86339$ & $17 / 88118$ \\
\hline third hour & $26 / 7322$ & $19 / 03758$ & $19 / 03408$ & $15 / 95678$ & $14 / 39983$ \\
\hline fourth hour & $28 / 25896$ & $29 / 22642$ & $25 / 56701$ & $18 / 42526$ & $13 / 53763$ \\
\hline fifth hour & $15 / 36752$ & $11 / 942$ & $8 / 529885$ & $10 / 47624$ & $9 / 462958$ \\
\hline
\end{tabular}

Table3. The scenarios of generative power of wind farm WF2 (MW) for a 5-hour time horizon

\begin{tabular}{|c|c|c|c|c|c|}
\hline $\begin{array}{c}\text { scenario } \\
\text { time horizon }\end{array}$ & 1 & 2 & 3 & 4 & 5 \\
\hline first hour & $18 / 66151$ & $21 / 5197$ & $19 / 1183$ & $14 / 94647$ & $12 / 54403$ \\
\hline second hour & $17 / 88118$ & $20 / 86527$ & $17 / 77029$ & $15 / 4554$ & $15 / 63204$ \\
\hline third hour & $14 / 39983$ & $12 / 76536$ & $9 / 60682$ & $5 / 788327$ & $3 / 239632$ \\
\hline fourth hour & $13 / 53763$ & $9 / 415776$ & $12 / 33214$ & $15 / 44921$ & $16 / 18289$ \\
\hline fifth hour & $25 / 46296$ & $12 / 81697$ & $18 / 17532$ & $10 / 4072$ & $9 / 078851$ \\
\hline
\end{tabular}

Table4. Consuming load scenarios of sample network for a 5-hour time horizon

\begin{tabular}{|c|c|c|c|c|c|}
\hline $\begin{array}{c}\text { scenario } \\
\text { time horizon }\end{array}$ & 1 & 2 & 3 & 4 & 5 \\
\hline first hour & $2085 / 413$ & $2332 / 737$ & $2484 / 277$ & $2361 / 46$ & $2452 / 632$ \\
\hline second hour & $2149 / 306$ & $2025 / 226$ & $2588 / 539$ & $3185 / 932$ & $3037 / 49$ \\
\hline third hour & $2433 / 506$ & $2261 / 663$ & $2410 / 814$ & $2476 / 723$ & $2620 / 521$ \\
\hline fourth hour & $2044 / 65$ & $2504 / 542$ & $1706 / 483$ & $1851 / 495$ & $1897 / 991$ \\
\hline fifth hour & $2409 / 223$ & $2935 / 693$ & $2104 / 62$ & $2061 / 184$ & $2079 / 617$ \\
\hline
\end{tabular}

\section{Simulation RESUltS AND DATA ANALYSIS}

The performed simulations relating to the introduced model for a short-term market settlement of reactive power were coded in GAMS software [13]. That is, the presented equations for reactive power market were implemented through a 5-hour scenario of different wind generative powers and requested load from the network in form of a nonlinear programming. Considering the span setting of reactive power generation for each unit and the need for binary variables, the Mixed Integer NonLinear programming method is adopted along with Discrete Continuous Optimizations for solving the problem of respective optimization in GAMS software. The results of generative active powers of thermal units 3 and 4 existent in the sample network are indicated in table 5 categorized based on scenarios and considering hours in the time horizon for each.

Table5. The hourly-dividedresults of generative active power of thermal units 3 and 4 in different scenarios

\begin{tabular}{|c|c|c|c|c|c|c|}
\hline $\begin{array}{c}\text { time } \\
\text { horizon }\end{array}$ & thermal unit & scenario 1 & scenario 2 & scenario 3 & scenario 4 & scenario 5 \\
\hline \multirow{2}{*}{4} & 3 & $15 / 2$ & $54 / 70068$ & $15 / 2$ & $15 / 2$ & $15 / 2$ \\
\cline { 2 - 7 } & 4 & $15 / 2$ & $54 / 70068$ & $15 / 2$ & $15 / 2$ & $152 /$ \\
\hline \multirow{2}{*}{5} & 3 & $15 / 2$ & $55 / 76139$ & $15 / 2$ & $15 / 2$ & $15 / 2$ \\
\cline { 2 - 7 } & 4 & $15 / 2$ & $26 / 78168$ & $15 / 2$ & $15 / 2$ & $15 / 2$ \\
\hline
\end{tabular}


Reactive Power Market-Management Considering Uncertainties of Load and Power of Wind Powerhouses

By comparing results represented in table 5 with the amounts of wind power generation and requested load shown in tables 2-4, one can perceive the impact of uncertain parameters' change of behavior in power system on the active power variable generated by thermal units existent in the network. This is the matter which is increasingly turning to be the major concern of power systems' exploiters in field of new energies and increasing their penetration in reconstructed spaces. For example, active power generation change of unit U3 can be pointed out in fourth and fifth hours of the second scenario where, in same hours, reached to $54.7 \mathrm{MW}$ and $55.7 \mathrm{MW}$ in the second scenarios compared to the first. The same rule holds for unit U4 generations in first and second scenarios in the same time horizon. The reason behind such thing in changing the planning of other units in different scenarios can be found in wind power generation alternations in the same hours of corresponding scenarios (including: a sharp decrease in generation of farm WF2 from 13.53MW in fourth hour to $9.4 \mathrm{MW}$ in the second scenario; a decrease of generation in first scenario in fifth hour from $25.46 \mathrm{MW}$ to 12.81 in the second scenario), as well as a rise of requested load in the network in the scenarios from fourth to fifth hour. The results of reactive powers generated by thermal units 9 and 10 existent in the sample short-term market divided based on scenarios and respective hours for a specific time horizon in each scenario are shown in tables 6-7.

Table6. The hourly-divided results of reactive power generated by thermal units 9 and 10 in the third area (Q3) in different scenarios

\begin{tabular}{|c|c|c|c|c|c|c|}
\hline thermal unit & time horizon & scenario 1 & scenario 2 & scenario 3 & scenario 4 & scenario 5 \\
\hline \multirow{4}{*}{9} & 1 & $23 / 98235$ & $2 / 592874$ & $3 / 257533$ & 60 & $3 / 422231$ \\
\cline { 2 - 7 } & 2 & $15 / 42051$ & 0 & $2 / 175198$ & $16 / 71302$ & $12 / 73655$ \\
\cline { 2 - 7 } & 3 & $39 / 6$ & $14 / 21405$ & 0 & $0 / 444243$ & $15 / 51827$ \\
\cline { 2 - 7 } & 4 & $39 / 6$ & $11 / 19298$ & $56 / 15606$ & $14 / 9204$ & $39 / 6$ \\
\cline { 2 - 7 } & 5 & 0 & $14 / 87355$ & 0 & $39 / 6$ & $7 / 761189$ \\
\cline { 2 - 7 } & 1 & $17 / 84735$ & $8 / 067463$ & $12 / 57559$ & $9 / 035753$ & $39 / 6$ \\
\cline { 2 - 7 } & 2 & $42 / 15009$ & 0 & $16 / 35313$ & $16 / 71302$ & $24 / 53061$ \\
\cline { 2 - 7 } & 4 & 0 & $28 / 89607$ & $27 / 5012$ & $0 / 093431$ & 0 \\
\cline { 2 - 7 } & 5 & $28 / 35456$ & $44 / 3198$ & $39 / 6$ & $2 / 37258$ & $6 / 113233$ \\
\hline
\end{tabular}

Table7. the hourly-divided results of reactive power generated by thermal units 9 and 10 in the second area (Q2) in different scenarios

\begin{tabular}{|c|c|c|c|c|c|c|}
\hline thermal unit & time horizon & scenario 1 & scenario 2 & scenario 3 & scenario 4 & scenario 5 \\
\hline \multirow{4}{*}{9} & 1 & $4 / 378586$ & $3 / 915034$ & $4 / 352122$ & $4 / 362555$ & $4 / 242365$ \\
\cline { 2 - 7 } & 2 & $4 / 320551$ & $3 / 421371$ & $4 / 09632$ & 6 & 6 \\
\cline { 2 - 7 } & 3 & $4 / 223969$ & $4 / 140246$ & $4 / 584703$ & $4 / 28391$ & $5 / 771845$ \\
\cline { 2 - 7 } & 4 & $6 / 05008$ & $6 / 404383$ & $4 / 167157$ & $3 / 051189$ & $4 / 364657$ \\
\cline { 2 - 7 } & 5 & $4 / 339774$ & $4 / 258219$ & $4 / 186856$ & $4 / 274605$ & $4 / 760276$ \\
\hline \multirow{4}{*}{10} & 1 & $5 / 107925$ & $3 / 915034$ & $4 / 789547$ & $5 / 516007$ & $4 / 251296$ \\
\cline { 2 - 7 } & 2 & $6 / 92058$ & $3 / 421371$ & $4 / 283927$ & $4 / 307433$ & $4 / 324412$ \\
\cline { 2 - 7 } & 4 & $4 / 223969$ & $4 / 140246$ & $4 / 584703$ & $4 / 28391$ & $4 / 271095$ \\
\cline { 2 - 7 } & 4 & $4 / 223284$ & $6 / 140343$ & $4 / 165437$ & $3 / 051189$ & $4 / 364657$ \\
\cline { 2 - 7 } & 5 & $4 / 33774$ & $4 / 258793$ & $4 / 187445$ & $4 / 274605$ & $4 / 760276$ \\
\hline
\end{tabular}

Since the objective of the present study (minimizing the costs of reactive power procurement) along with technical impacts of existent uncertainties of the results relating to the total costs of power procurement (mentioned in table 8) could be regarded as an economic incentive, it may be used by power systems exploiters to have an extensive plan taking into account the impacts of newly-appeared issues of the systems (like probability behavior changes of renewable sources).

Table8. The total costs, the whole active/reactive powers generated by thermal units along with all scenarios' information

\begin{tabular}{|c|c|c|c|c|c|}
\hline & scenario 1 & scenario 2 & scenario 3 & scenario 4 & scenario 5 \\
\hline total cost (\$) & $1565 / 6$ & $1348 / 1$ & $1239 / 7$ & $1971 / 6$ & $1284 / 3$ \\
\hline $\begin{array}{c}\text { total Demand } \\
(\mathrm{MW})\end{array}$ & 11948 & $13235 / 73$ & $12463 / 96$ & $10215 / 9$ & $11836 / 72$ \\
\hline $\begin{array}{c}\text { total Wind } \\
\text { generation } \\
(\mathrm{MW})\end{array}$ & 201 & $193 / 73$ & $140 / 96$ & $181 / 9$ & $131 / 72$ \\
\hline
\end{tabular}


Reactive Power Market-Management Considering Uncertainties of Load and Power of Wind Powerhouses

\begin{tabular}{|c|c|c|c|c|c|}
\hline $\begin{array}{c}\text { total Active } \\
\text { Power } \\
\begin{array}{c}\text { Generation } \\
\text { (MW) }\end{array}\end{array}$ & 11747 & 13042 & 12323 & 10034 & 11705 \\
\hline $\begin{array}{c}\text { total Reactive } \\
\text { Power } \\
\text { Procurement } \\
\text { (MVar) }\end{array}$ & 573 & 601 & 589 & 565 & 570 \\
\hline
\end{tabular}

\section{Conclusions}

Regarding the appearance and rise of using renewable sources, and existent uncertainties in power generation in this field, on one side, and variable behavior of some parameters in power system including demanded load of consumers, on the other side, the issue of probability planning in power systems and the involving markets is of high importance about which much attention has been paid. Therefore, the present study, in this direction, represents a model of probability planning for power producers' activity in reactive power market so that the issues of minimizing network-demanded reactive power procurement costs, as well as taking wind power uncertainties and network load into account, are considered. As is observed in the below tables, the wind power fluctuations, as one the active power generation sources in the network, have significant influence on thermal units' performance in (technically) providing the network reactive power; also, considerably (economically) affect the costs rate of this field. As is shown in the simulation results of the present study, economictechnical impacts of applying present uncertainties on different parameters of the power network in the market is considerable. What was majorly studied in this paper was assessing these economictechnical impacts on power producers' activity in the reactive power short-term market aiming at minimizing the costs of providing reactive power in electricity market. Through a comprehensive analysis of these impacts, on one side, and economically analyzing behavioral changes of probability parameters in power system (including wind power generation), on the other side, real results and patterns can be obtained which are capable of being implemented in power operational networks.

\section{ACKNOWLEDGEMENTS}

I would like to thanks Dr. Dr. Mohsen Simab for his practical, influential guidance. Also, I dedicate this paper to my kind wife.

\section{Appendices}

Generative reactive power of thermal units in the first area

\begin{tabular}{|c|c|c|c|c|c|c|}
\hline $\begin{array}{c}\text { thermal } \\
\text { unit }\end{array}$ & time horizon & scenario 1 & scenario 2 & scenario 3 & scenario 4 & scenario 5 \\
\hline 1 & 1 & 16 & 16 & 16 & 16 & 16 \\
\hline & 2 & 16 & 16 & 16 & 16 & 20 \\
\hline & 3 & 16 & 16 & 16 & 16 & 16 \\
\hline & 4 & 16 & 20 & 16 & 16 & 16 \\
\hline & 5 & 16 & 20 & 16 & 16 & 16 \\
\hline 2 & 1 & 16 & 16 & 16 & 16 & 16 \\
\hline & 2 & 16 & 16 & 16 & 16 & 20 \\
\hline & 3 & 16 & 16 & 16 & 16 & 16 \\
\hline & 4 & 16 & 20 & 16 & 16 & 16 \\
\hline & 5 & 16 & 20 & 16 & 16 & 16 \\
\hline 3 & 1 & $15 / 2$ & $15 / 2$ & $15 / 2$ & $15 / 2$ & $15 / 2$ \\
\hline & 2 & $15 / 2$ & $15 / 2$ & $15 / 25$ & $15 / 2$ & $15 / 2$ \\
\hline & 3 & $15 / 2$ & $15 / 2$ & $15 / 2$ & $15 / 2$ & $15 / 2$ \\
\hline & 4 & $15 / 2$ & $54 / 70068$ & $15 / 2$ & $15 / 2$ & $15 / 2$ \\
\hline & 5 & $15 / 2$ & $55 / 76139$ & $15 / 2$ & $15 / 2$ & $15 / 2$ \\
\hline 4 & 1 & $15 / 2$ & $15 / 2$ & $15 / 2$ & $15 / 2$ & $15 / 2$ \\
\hline & 2 & $15 / 2$ & $15 / 2$ & $15 / 2$ & $15 / 2$ & $15 / 2$ \\
\hline & 3 & $15 / 2$ & $15 / 2$ & $15 / 2$ & $15 / 2$ & $15 / 2$ \\
\hline & 4 & $15 / 2$ & $54 / 70068$ & $15 / 2$ & $15 / 2$ & $15 / 2$ \\
\hline
\end{tabular}


Reactive Power Market-Management Considering Uncertainties of Load and Power of Wind Powerhouses

\begin{tabular}{|c|c|c|c|c|c|c|}
\hline \multirow[t]{5}{*}{5} & 1 & 16 & 16 & 16 & 16 & 16 \\
\hline & 2 & 16 & 16 & 16 & 16 & 16 \\
\hline & 3 & 16 & 16 & 16 & 16 & 16 \\
\hline & 4 & 16 & 20 & 16 & 16 & 16 \\
\hline & 5 & 16 & 20 & 16 & 16 & 16 \\
\hline \multirow[t]{5}{*}{6} & 1 & 16 & 16 & 16 & 16 & 16 \\
\hline & 2 & 16 & 16 & 16 & 16 & 20 \\
\hline & 3 & 16 & 16 & 16 & 16 & 16 \\
\hline & 4 & 16 & 20 & 16 & 16 & 16 \\
\hline & 5 & 16 & 20 & 16 & 16 & 16 \\
\hline \multirow[t]{5}{*}{7} & 1 & $15 / 2$ & $15 / 2$ & $15 / 2$ & $15 / 2$ & $15 / 2$ \\
\hline & 2 & $15 / 2$ & $15 / 2$ & $15 / 2$ & $15 / 2$ & $15 / 2$ \\
\hline & 3 & $15 / 2$ & $15 / 2$ & $15 / 2$ & $15 / 2$ & $15 / 2$ \\
\hline & 4 & $15 / 2$ & $64 / 0693$ & $15 / 2$ & $15 / 2$ & $15 / 2$ \\
\hline & 5 & $15 / 2$ & $75 / 34031$ & $15 / 2$ & $15 / 2$ & $15 / 2$ \\
\hline \multirow[t]{5}{*}{8} & 1 & $15 / 2$ & $15 / 2$ & $15 / 2$ & $15 / 2$ & $15 / 2$ \\
\hline & 2 & $15 / 2$ & $15 / 2$ & $15 / 2$ & $15 / 2$ & 76 \\
\hline & 3 & $15 / 2$ & $15 / 2$ & $15 / 2$ & $15 / 2$ & $15 / 2$ \\
\hline & 4 & $15 / 2$ & $54 / 69773$ & $15 / 2$ & $15 / 2$ & $15 / 2$ \\
\hline & 5 & $15 / 2$ & $26 / 21841$ & $15 / 2$ & $15 / 2$ & $15 / 2$ \\
\hline \multirow[t]{5}{*}{9} & 1 & 25 & 25 & $68 / 30924$ & 25 & $25 / 87671$ \\
\hline & 2 & 25 & 25 & $45 / 75193$ & $70 / 73608$ & 100 \\
\hline & 3 & $30 / 85775$ & $99 / 35983$ & $45 / 51094$ & 25 & 25 \\
\hline & 4 & 25 & 100 & 25 & 25 & $47 / 26501$ \\
\hline & 5 & 100 & 100 & 100 & 25 & 25 \\
\hline \multirow[t]{5}{*}{10} & 1 & 25 & 25 & $33 / 10224$ & 25 & $25 / 87671$ \\
\hline & 2 & 25 & 25 & $31 / 84528$ & $25 / 23451$ & 100 \\
\hline & 3 & $30 / 85775$ & 25 & $25 / 64102$ & 25 & 25 \\
\hline & 4 & 100 & 100 & 100 & 25 & 25 \\
\hline & 5 & $65 / 08506$ & 100 & 100 & 25 & 25 \\
\hline \multirow[t]{5}{*}{11} & 1 & 25 & 25 & 25 & $39 / 12687$ & $80 / 32408$ \\
\hline & 2 & 25 & 25 & $31 / 84528$ & $25 / 23451$ & 100 \\
\hline & 3 & $38 / 92562$ & 25 & $25 / 64102$ & 25 & 25 \\
\hline & 4 & 100 & 100 & $42 / 40915$ & 25 & 25 \\
\hline & 5 & 25 & 100 & 100 & 25 & 25 \\
\hline \multirow[t]{5}{*}{12} & 1 & 197 & 197 & 197 & 197 & 197 \\
\hline & 2 & 197 & 197 & 197 & 197 & 197 \\
\hline & 3 & 197 & 197 & 197 & $159 / 5633$ & $168 / 6183$ \\
\hline & 4 & 197 & 197 & 197 & 197 & 197 \\
\hline & 5 & 197 & 197 & 197 & 197 & 197 \\
\hline \multirow[t]{5}{*}{13} & 1 & 197 & 197 & 197 & 197 & 197 \\
\hline & 2 & 197 & 197 & 197 & 197 & 197 \\
\hline & 3 & 197 & 197 & 197 & 197 & 197 \\
\hline & 4 & 69 & 197 & 197 & $141 / 9656$ & 197 \\
\hline & 5 & 197 & 197 & 197 & 197 & 197 \\
\hline \multirow[t]{5}{*}{14} & 1 & 197 & 197 & 197 & 197 & 197 \\
\hline & 2 & 197 & 197 & 197 & 197 & 197 \\
\hline & 3 & 197 & 197 & 197 & 69 & 197 \\
\hline & 4 & 69 & 197 & 197 & $134 / 8392$ & 197 \\
\hline & 5 & 197 & 197 & 197 & 69 & 197 \\
\hline \multirow[t]{5}{*}{16} & 1 & $2 / 4$ & $2 / 4$ & $2 / 4$ & $2 / 4$ & $2 / 4$ \\
\hline & 2 & $2 / 4$ & $2 / 4$ & $2 / 4$ & $2 / 4$ & $2 / 4$ \\
\hline & 3 & $2 / 4$ & $2 / 4$ & $2 / 4$ & $2 / 4$ & $2 / 4$ \\
\hline & 4 & $2 / 4$ & $2 / 929364$ & $2 / 4$ & $2 / 4$ & $2 / 4$ \\
\hline & 5 & $2 / 4$ & $2 / 4$ & $2 / 4$ & $2 / 4$ & $2 / 4$ \\
\hline \multirow[t]{4}{*}{17} & 1 & $2 / 4$ & $2 / 4$ & $2 / 4$ & $2 / 4$ & $2 / 4$ \\
\hline & 2 & $2 / 4$ & $2 / 4$ & $2 / 4$ & $2 / 4$ & $2 / 4$ \\
\hline & 3 & $2 / 4$ & $2 / 4$ & $2 / 4$ & $2 / 4$ & $2 / 4$ \\
\hline & 4 & $2 / 4$ & $2 / 932548$ & $2 / 4$ & $2 / 4$ & $2 / 4$ \\
\hline
\end{tabular}


Reactive Power Market-Management Considering Uncertainties of Load and Power of Wind Powerhouses

\begin{tabular}{|c|c|c|c|c|c|c|}
\hline & 5 & $2 / 4$ & $2 / 4$ & $2 / 4$ & $2 / 4$ & $2 / 4$ \\
\hline \multirow[t]{5}{*}{18} & 1 & $2 / 4$ & $2 / 4$ & $2 / 4$ & $2 / 4$ & $2 / 4$ \\
\hline & 2 & $2 / 4$ & $2 / 4$ & $2 / 4$ & $2 / 4$ & $2 / 4$ \\
\hline & 3 & $2 / 4$ & $2 / 4$ & $2 / 4$ & $2 / 4$ & $2 / 4$ \\
\hline & 4 & $2 / 4$ & $2 / 932548$ & $2 / 4$ & $2 / 4$ & $2 / 4$ \\
\hline & 5 & $2 / 4$ & $2 / 4$ & $2 / 4$ & $2 / 4$ & $2 / 4$ \\
\hline \multirow[t]{5}{*}{1} & 1 & $2 / 4$ & $2 / 4$ & $2 / 4$ & $2 / 4$ & $2 / 4$ \\
\hline & 2 & $2 / 4$ & $2 / 4$ & $2 / 4$ & $2 / 4$ & $2 / 4$ \\
\hline & 3 & $2 / 4$ & $2 / 4$ & $2 / 4$ & $2 / 4$ & $2 / 4$ \\
\hline & 4 & $2 / 4$ & $2 / 932548$ & $2 / 4$ & $2 / 4$ & $2 / 4$ \\
\hline & 5 & $2 / 4$ & $2 / 4$ & $2 / 4$ & $2 / 4$ & $2 / 4$ \\
\hline \multirow[t]{5}{*}{20} & 1 & $2 / 4$ & $2 / 4$ & $2 / 4$ & $2 / 4$ & $2 / 4$ \\
\hline & 2 & $2 / 4$ & $2 / 4$ & $2 / 4$ & $2 / 4$ & $2 / 4$ \\
\hline & 3 & $2 / 4$ & $2 / 4$ & $2 / 4$ & $2 / 4$ & $2 / 4$ \\
\hline & 4 & $2 / 4$ & $2 / 932548$ & $2 / 4$ & $2 / 4$ & $2 / 4$ \\
\hline & 5 & $2 / 4$ & $2 / 4$ & $2 / 4$ & $2 / 4$ & $2 / 4$ \\
\hline \multirow[t]{5}{*}{21} & 1 & $98 / 19867$ & $54 / 3$ & $144 / 3446$ & $54 / 3$ & $132 / 3994$ \\
\hline & 2 & $114 / 8854$ & $54 / 3$ & $54 / 3$ & 155 & 155 \\
\hline & 3 & $152 / 8752$ & 155 & $143 / 8152$ & $54 / 3$ & $77 / 49212$ \\
\hline & 4 & $54 / 3$ & 155 & 155 & $54 / 3$ & $54 / 3$ \\
\hline & 5 & $54 / 3$ & 155 & 155 & $54 / 3$ & $105 / 9393$ \\
\hline \multirow[t]{5}{*}{22} & 1 & $54 / 3$ & 155 & $144 / 2652$ & $54 / 3$ & $130 / 4599$ \\
\hline & 2 & 155 & $90 / 64175$ & $82 / 94093$ & 155 & 155 \\
\hline & 3 & $128 / 6109$ & 155 & 155 & $54 / 3$ & $120 / 2245$ \\
\hline & 4 & $125 / 2912$ & 155 & 155 & $54 / 3$ & $54 / 3$ \\
\hline & 5 & 155 & 155 & 155 & $54 / 3$ & $54 / 3$ \\
\hline \multirow[t]{5}{*}{23} & 1 & 400 & $351 / 3674$ & 400 & 400 & 400 \\
\hline & 2 & 400 & 400 & 400 & 400 & 400 \\
\hline & 3 & 400 & 400 & 400 & $224 / 6442$ & 400 \\
\hline & 4 & 400 & 400 & 400 & 400 & 400 \\
\hline & 5 & 400 & 400 & 400 & 400 & 400 \\
\hline \multirow[t]{5}{*}{24} & 1 & 400 & 400 & 400 & 400 & 400 \\
\hline & 2 & $387 / 0054$ & 400 & 400 & 400 & 400 \\
\hline & 3 & 400 & 400 & 400 & 400 & 400 \\
\hline & 4 & 400 & 400 & 400 & 400 & $397 / 9357$ \\
\hline & 5 & 400 & 400 & $354 / 4881$ & $380 / 589$ & 400 \\
\hline \multirow[t]{5}{*}{25} & 1 & 10 & 10 & 10 & 10 & 10 \\
\hline & 2 & 10 & 10 & 10 & 10 & $13 / 11476$ \\
\hline & 3 & 10 & 10 & 10 & 10 & 10 \\
\hline & 4 & 10 & $43 / 42894$ & 10 & 10 & 10 \\
\hline & 5 & 10 & $21 / 07577$ & 10 & 10 & 10 \\
\hline \multirow[t]{5}{*}{26} & 1 & 10 & 10 & 10 & 10 & 10 \\
\hline & 2 & 10 & 10 & 10 & 10 & $15 / 7226$ \\
\hline & 3 & 10 & 10 & 10 & 10 & 10 \\
\hline & 4 & 10 & $42 / 13394$ & 10 & 10 & 10 \\
\hline & 5 & 10 & $19 / 33854$ & 10 & 10 & 10 \\
\hline \multirow[t]{5}{*}{27} & 1 & 10 & 10 & 10 & 10 & 10 \\
\hline & 2 & 10 & 10 & 10 & 10 & $16 / 09663$ \\
\hline & 3 & 10 & 10 & 10 & 10 & 10 \\
\hline & 4 & 10 & $43 / 42894$ & 10 & 10 & 10 \\
\hline & 5 & 10 & $19 / 43939$ & 10 & 10 & 10 \\
\hline \multirow[t]{5}{*}{28} & 1 & 10 & 10 & 10 & 10 & 10 \\
\hline & 2 & 10 & 10 & 10 & 10 & $16 / 09663$ \\
\hline & 3 & 10 & 10 & 10 & 10 & 10 \\
\hline & 4 & 10 & $30 / 94937$ & 10 & 10 & 10 \\
\hline & 5 & 10 & $19 / 43939$ & 10 & 10 & 10 \\
\hline \multirow[t]{3}{*}{29} & 1 & 10 & 10 & 10 & 10 & 10 \\
\hline & 2 & 10 & 10 & 10 & 10 & $16 / 09663$ \\
\hline & 3 & 10 & 10 & 10 & 10 & 10 \\
\hline
\end{tabular}


Reactive Power Market-Management Considering Uncertainties of Load and Power of Wind Powerhouses

\begin{tabular}{|l|l|c|c|c|c|c|}
\hline & 4 & 10 & $30 / 82451$ & 10 & 10 & 10 \\
\hline & 5 & 10 & $17 / 73565$ & 10 & 10 & 10 \\
\hline 30 & 1 & 10 & 10 & 10 & 10 & 10 \\
\hline & 2 & 10 & 10 & 10 & 10 & $16 / 09663$ \\
\hline & 3 & 10 & 10 & 10 & 10 & 10 \\
\hline & 4 & 10 & $32 / 14627$ & 10 & 10 & 10 \\
\hline & 5 & 10 & $18 / 01772$ & 10 & 10 & 10 \\
\hline & 1 & $54 / 3$ & 155 & $144 / 0254$ & $60 / 85729$ & $151 / 282$ \\
\hline & 2 & $54 / 3$ & $70 / 5448$ & $69 / 34597$ & 155 & 155 \\
\hline & 3 & 155 & 155 & 155 & $54 / 3$ & $67 / 20938$ \\
\hline & 4 & 155 & 155 & 155 & $66 / 80647$ & $54 / 3$ \\
\hline & 5 & $112 / 9585$ & 155 & 155 & $54 / 3$ & $54 / 3$ \\
\hline & 1 & $54 / 3$ & $54 / 3$ & $145 / 8129$ & $60 / 85729$ & $138 / 7244$ \\
\hline & 2 & $95 / 97297$ & $70 / 5448$ & $115 / 0467$ & 155 & 155 \\
\hline & 3 & 155 & 155 & 155 & $54 / 3$ & $67 / 20938$ \\
\hline & 4 & 155 & 155 & $118 / 7039$ & $66 / 80647$ & $54 / 3$ \\
\hline & 5 & $131 / 6659$ & 155 & 155 & $54 / 3$ & $54 / 3$ \\
\hline & 1 & 350 & $342 / 7553$ & 350 & $259 / 377$ & 350 \\
\hline & 2 & 350 & 350 & 350 & 350 & 350 \\
\hline & 3 & 350 & $321 / 4151$ & $344 / 2829$ & 350 & 350 \\
\hline & 4 & 350 & 350 & 350 & 350 & 350 \\
\hline & 5 & 350 & 350 & $323 / 9938$ & 350 & 350 \\
\hline
\end{tabular}

Generative reactive power of thermal units in the second area

\begin{tabular}{|c|c|c|c|c|c|c|}
\hline $\begin{array}{l}\text { thermal } \\
\text { unit }\end{array}$ & time horizon & scenario 1 & scenario 2 & scenario 3 & scenario 4 & scenario 5 \\
\hline \multirow[t]{5}{*}{1} & 1 & $0 / 898662$ & $0 / 905219$ & $0 / 897008$ & $0 / 897744$ & $0 / 890148$ \\
\hline & 2 & $0 / 895034$ & $0 / 800009$ & $0 / 892745$ & $0 / 894215$ & $0 / 895276$ \\
\hline & 3 & $0 / 888998$ & $0 / 883765$ & $0 / 911544$ & $0 / 892744$ & $0 / 891943$ \\
\hline & 4 & $0 / 888955$ & $0 / 879161$ & $0 / 88534$ & $0 / 805978$ & $0 / 897791$ \\
\hline & 5 & $0 / 896236$ & $0 / 891175$ & $0 / 886715$ & $0 / 892163$ & $0 / 894661$ \\
\hline \multirow[t]{5}{*}{2} & 1 & $0 / 88662$ & $0 / 905219$ & $0 / 897008$ & $0 / 897744$ & $0 / 890148$ \\
\hline & 2 & $0 / 895034$ & $0 / 800009$ & $0 / 892745$ & $0 / 894215$ & $0 / 895276$ \\
\hline & 3 & $0 / 888998$ & $0 / 883765$ & $0 / 911544$ & $0 / 892744$ & $0 / 891943$ \\
\hline & 4 & $0 / 888955$ & $0 / 879161$ & $0 / 88534$ & $0 / 805978$ & $0 / 897791$ \\
\hline & 5 & $0 / 896236$ & $0 / 891175$ & $0 / 886715$ & $0 / 892163$ & $0 / 894661$ \\
\hline \multirow[t]{5}{*}{3} & 1 & $2 / 594646$ & $2 / 620876$ & $2 / 588031$ & $2 / 590981$ & $2 / 560591$ \\
\hline & 2 & $2 / 579597$ & $2 / 200035$ & $2 / 570982$ & $2 / 576858$ & $2 / 581103$ \\
\hline & 3 & $2 / 555992$ & $2 / 535062$ & $2 / 646176$ & $2 / 570977$ & $2 / 567774$ \\
\hline & 4 & $2 / 555812$ & $2 / 516831$ & $2 / 541359$ & $2 / 223914$ & $2 / 591164$ \\
\hline & 5 & $2 / 584943$ & $2 / 564698$ & $2 / 546861$ & $2 / 56861$ & $2 / 578644$ \\
\hline \multirow[t]{5}{*}{4} & 1 & 2.594646 & 2.620876 & 2.588031 & $5 / 590981$ & $2 / 560591$ \\
\hline & 2 & $2 / 579604$ & $2 / 200035$ & $2 / 570982$ & $2 / 576858$ & $2 / 581103$ \\
\hline & 3 & $2 / 555992$ & $2 / 535062$ & $2 / 646176$ & $2 / 570977$ & $2 / 567774$ \\
\hline & 4 & $2 / 555821$ & $2 / 51626$ & $2 / 541359$ & $2 / 223914$ & $2 / 591164$ \\
\hline & 5 & $2 / 584943$ & $2 / 564698$ & $2 / 546861$ & $2 / 568651$ & $2 / 578644$ \\
\hline \multirow[t]{5}{*}{5} & 1 & $0 / 898662$ & $0 / 905219$ & $0 / 897008$ & $0 / 897743$ & $0 / 890148$ \\
\hline & 2 & $0 / 895034$ & $0 / 800009$ & $0 / 892745$ & $0 / 894215$ & $0 / 895276$ \\
\hline & 3 & $0 / 888998$ & $0 / 883765$ & $0 / 911544$ & $0 / 892744$ & $0 / 891943$ \\
\hline & 4 & $0 / 888955$ & $0 / 879161$ & $0 / 88534$ & $0 / 805978$ & $0 / 897791$ \\
\hline & 5 & $0 / 896236$ & $0 / 891175$ & $0 / 886715$ & $0 / 892163$ & $0 / 894661$ \\
\hline \multirow[t]{5}{*}{6} & 1 & $0 / 898662$ & $0 / 905219$ & $0 / 897008$ & $0 / 897743$ & $0 / 890148$ \\
\hline & 2 & $0 / 895034$ & $0 / 800009$ & $0 / 892745$ & $0 / 894215$ & $0 / 895276$ \\
\hline & 3 & 08888998 & $0 / 883765$ & $0 / 911544$ & $0 / 892744$ & $0 / 891943$ \\
\hline & 4 & $0 / 888955$ & $0 / 879161$ & $0 / 88534$ & $0 / 805978$ & $0 / 897791$ \\
\hline & 5 & $0 / 896236$ & $0 / 891175$ & $0 / 886715$ & $0 / 892163$ & $0 / 894661$ \\
\hline \multirow[t]{3}{*}{7} & 1 & $2 / 594646$ & $2 / 620876$ & $2 / 588031$ & $2 / 590981$ & $2 / 560591$ \\
\hline & 2 & $2 / 57958$ & $2 / 200035$ & $2 / 570982$ & $2 / 576858$ & $2 / 581103$ \\
\hline & 3 & $2 / 555992$ & $2 / 535062$ & $2 / 646176$ & $2 / 570977$ & $2 / 567774$ \\
\hline
\end{tabular}

International Journal of Research Studies in Electrical and Electronics Engineering (IJRSEEE) Page | 51 
Reactive Power Market-Management Considering Uncertainties of Load and Power of Wind Powerhouses

\begin{tabular}{|c|c|c|c|c|c|c|}
\hline & 4 & $2 / 555821$ & $4 / 092383$ & $2 / 541359$ & $2 / 223914$ & $2 / 591164$ \\
\hline & 5 & $2 / 584941$ & $2 / 564698$ & $2 / 546861$ & $2 / 568651$ & $2 / 578644$ \\
\hline \multirow[t]{5}{*}{8} & 1 & $2 / 594646$ & $2 / 620876$ & $2 / 588031$ & $2 / 590981$ & $2 / 56051$ \\
\hline & 2 & $2 / 580138$ & $3 / 300035$ & $2 / 570982$ & $2 / 576858$ & $2 / 581103$ \\
\hline & 3 & $2 / 555992$ & $2 / 535062$ & $2 / 64176$ & $2 / 570977$ & $2 / 567774$ \\
\hline & 4 & $2 / 555821$ & $2 / 516723$ & $2 / 541359$ & $2 / 223914$ & $2 / 591164$ \\
\hline & 5 & $2 / 584874$ & $2 / 564698$ & $2 / 546861$ & $2 / 568651$ & $2 / 578644$ \\
\hline \multirow[t]{5}{*}{9} & 1 & $4 / 378586$ & $3 / 915034$ & $4 / 352122$ & $4 / 362555$ & $4 / 242365$ \\
\hline & 2 & $4 / 320551$ & $3 / 421371$ & $4 / 09632$ & 6 & 6 \\
\hline & 3 & $4 / 223969$ & $4 / 140246$ & $4 / 584703$ & $4 / 28391$ & $5 / 771845$ \\
\hline & 4 & 6805008 & $6 / 404383$ & $4 / 167157$ & $3 / 051189$ & $4 / 364657$ \\
\hline & 5 & $4 / 339774$ & $4 / 258219$ & $4 / 186856$ & $4 / 274605$ & $4 / 760276$ \\
\hline \multirow[t]{5}{*}{10} & 1 & $5 / 107925$ & $3 / 915034$ & $4 / 789547$ & $5 / 516007$ & $4 / 251296$ \\
\hline & 2 & $6 / 92058$ & $3 / 421371$ & $4 / 283927$ & $4 / 307433$ & $4 / 324412$ \\
\hline & 3 & $4 / 223969$ & $4 / 140246$ & $4 / 584703$ & $4 / 28391$ & $4 / 271095$ \\
\hline & 4 & $4 / 223284$ & $6 / 140343$ & $4 / 165437$ & $3 / 051189$ & $4 / 364657$ \\
\hline & 5 & $4 / 339774$ & $4 / 258793$ & $4 / 187445$ & $4 / 274605$ & $4 / 760276$ \\
\hline \multirow[t]{5}{*}{11} & 1 & $4 / 378586$ & $3 / 915034$ & $4 / 377729$ & $4 / 363926$ & $4 / 242365$ \\
\hline & 2 & $4 / 320551$ & $3 / 421371$ & $4 / 283927$ & $4 / 307433$ & $4 / 324412$ \\
\hline & 3 & $4 / 223969$ & $4 / 140246$ & $4 / 584703$ & $4 / 28391$ & $4 / 271095$ \\
\hline & 4 & $4 / 223284$ & $6 / 140343$ & $4 / 165437$ & $3 / 051189$ & $4 / 364657$ \\
\hline & 5 & $5 / 024927$ & $4 / 258793$ & $4 / 187445$ & $4 / 274605$ & $4 / 314576$ \\
\hline \multirow[t]{5}{*}{12} & 1 & 8 & 8 & $6 / 352118$ & 8 & $6 / 242361$ \\
\hline & 2 & 8 & $8 / 293182$ & $6 / 283923$ & $6 / 307429$ & $6 / 324408$ \\
\hline & 3 & $6 / 223965$ & $6 / 140242$ & $6 / 584699$ & $6 / 286124$ & $6 / 271091$ \\
\hline & 4 & $6 / 22328$ & $6 / 066573$ & $6 / 165433$ & 8 & $6 / 364653$ \\
\hline & 5 & $6 / 33977$ & $6 / 258789$ & $6 / 187441$ & $6 / 274601$ & $6 / 314572$ \\
\hline \multirow[t]{5}{*}{13} & 1 & $6 / 378581$ & 8 & $6 / 352118$ & 8 & $6 / 242361$ \\
\hline & 2 & 8 & $4 / 800135$ & $6 / 283923$ & $6 / 307429$ & $6 / 324408$ \\
\hline & 3 & $6 / 22395$ & $6 / 140242$ & $6 / 584699$ & 18.87996 & $6 / 271091$ \\
\hline & 4 & $6 / 22328$ & $6 / 066573$ & $6 / 165433$ & $4 / 89565$ & $6 / 364653$ \\
\hline & 5 & $6 / 33977$ & $6 / 258789$ & $6 / 187441$ & $6 / 274601$ & $6 / 314572$ \\
\hline \multirow[t]{5}{*}{14} & 1 & $6 / 378581$ & 8 & $6 / 352118$ & 8 & $6 / 242361$ \\
\hline & 2 & 8 & $4 / 800135$ & $6 / 283923$ & $6 / 307429$ & $6 / 324408$ \\
\hline & 3 & $6 / 223965$ & $6 / 140242$ & $6 / 584699$ & $6 / 286124$ & $6 / 271091$ \\
\hline & 4 & $6 / 22328$ & $6 / 066573$ & $6 / 165433$ & $4 / 89565$ & $6 / 364653$ \\
\hline & 5 & $6 / 33977$ & $6 / 258789$ & $6 / 6 / 187441$ & $6 / 274601$ & $6 / 314572$ \\
\hline \multirow[t]{5}{*}{15} & 1 & $10 / 12271$ & $8 / 269161$ & $10 / 01686$ & 20 & $9 / 57783$ \\
\hline & 2 & $9 / 890571$ & $6 / 320603$ & 9/744078 & $9 / 838103$ & $9 / 906017$ \\
\hline & 3 & $9 / 504246$ & $9 / 169353$ & $10 / 94718$ & $0 / 023832$ & $9 / 692748$ \\
\hline & 4 & $9 / 501506$ & 7/99964 & $9 / 270118$ & $4 / 813124$ & $10 / 06924$ \\
\hline & 5 & $9 / 967464$ & $32 / 79537$ & 0 & $4 / 538159$ & $9 / 866674$ \\
\hline \multirow[t]{5}{*}{16} & 1 & $0 / 498662$ & $0 / 505219$ & $0 / 497008$ & $0 / 497745$ & $0 / 490148$ \\
\hline & 2 & $0 / 495034$ & $0 / 400009$ & $0 / 492745$ & $0 / 494215$ & $0 / 495276$ \\
\hline & 3 & $0 / 488998$ & $0 / 483765$ & $0 / 511544$ & $0 / 492744$ & $0 / 491943$ \\
\hline & 4 & $0 / 488955$ & $0 / 479161$ & $0 / 48534$ & $0 / 405978$ & $0 / 497791$ \\
\hline & 5 & $0 / 496236$ & $0 / 491175$ & $0 / 486715$ & $0 / 492163$ & $0 / 494661$ \\
\hline \multirow[t]{5}{*}{17} & 1 & $0 / 498662$ & $0 / 505219$ & $0 / 497008$ & $0 / 497745$ & $0 / 490148$ \\
\hline & 2 & $0 / 495034$ & $0 / 400009$ & $0 / 492745$ & $0 / 494215$ & $0 / 495276$ \\
\hline & 3 & $0 / 488998$ & $0 / 483765$ & $0 / 511544$ & $0 / 492744$ & $0 / 491943$ \\
\hline & 4 & $0 / 488955$ & $0 / 479161$ & $0 / 48534$ & $0 / 405978$ & $0 / 497791$ \\
\hline & 5 & $0 / 496236$ & $0 / 491175$ & $0 / 486715$ & $0 / 492163$ & $0 / 494661$ \\
\hline \multirow[t]{5}{*}{18} & 1 & $0 / 498662$ & $0 / 505219$ & $0 / 497008$ & $0 / 497745$ & $0 / 490148$ \\
\hline & 2 & $0 / 495034$ & $0 / 400009$ & $0 / 492745$ & $0 / 494215$ & $0 / 495276$ \\
\hline & 3 & $0 / 488998$ & $0 / 483765$ & $0 / 511544$ & $0 / 492744$ & $0 / 491943$ \\
\hline & 4 & $0 / 488955$ & $0 / 479161$ & $0 / 48534$ & $0 / 405978$ & $0 / 497791$ \\
\hline & 5 & $0 / 496236$ & $0 / 491175$ & $0 / 486715$ & $0 / 492163$ & $0 / 494661$ \\
\hline \multirow[t]{2}{*}{19} & 1 & $0 / 498662$ & $0 / 505219$ & $0 / 497008$ & $0 / 497745$ & $0 / 490148$ \\
\hline & 2 & $0 / 495034$ & $0 / 400009$ & $0 / 492745$ & $0 / 494215$ & $0 / 495276$ \\
\hline
\end{tabular}


Reactive Power Market-Management Considering Uncertainties of Load and Power of Wind Powerhouses

\begin{tabular}{|c|c|c|c|c|c|c|}
\hline & 3 & $0 / 488998$ & $0 / 483765$ & $0 / 511544$ & $0 / 492744$ & $0 / 491943$ \\
\hline & 4 & $0 / 488955$ & $0 / 479161$ & $0 / 48534$ & $0 / 405978$ & $0 / 497791$ \\
\hline & 5 & $0 / 496236$ & $0 / 491175$ & $0 / 486715$ & $0 / 492163$ & $0 / 494661$ \\
\hline \multirow[t]{5}{*}{20} & 1 & $0 / 498662$ & $0 / 505219$ & $0 / 497008$ & $0 / 497745$ & $0 / 490148$ \\
\hline & 2 & $0 / 495034$ & $0 / 400009$ & $0 / 492745$ & $0 / 494215$ & $0 / 495276$ \\
\hline & 3 & $0 / 488998$ & $0 / 483765$ & $0 / 511544$ & $0 / 492744$ & $0 / 491943$ \\
\hline & 4 & $0 / 488955$ & $0 / 479161$ & $0 / 48534$ & $0 / 405978$ & $0 / 497791$ \\
\hline & 5 & $0 / 496236$ & $0 / 491175$ & $0 / 486715$ & $0 / 492163$ & $0 / 494661$ \\
\hline \multirow[t]{5}{*}{21} & 1 & $6 / 378581$ & $6 / 482342$ & $6 / 39929$ & $3 / 284608$ & $6 / 242361$ \\
\hline & 2 & $6 / 320546$ & $4 / 800135$ & $6 / 241772$ & $6 / 307429$ & $6 / 324408$ \\
\hline & 3 & $6 / 223965$ & $6 / 140242$ & $6 / 584699$ & $6 / 287336$ & $6 / 271091$ \\
\hline & 4 & $6 / 22328$ & $6 / 066569$ & $6 / 165433$ & $4 / 89565$ & $6 / 364653$ \\
\hline & 5 & 8 & $6 / 14275$ & $51 / 02359$ & $6 / 472362$ & $12 / 24771$ \\
\hline \multirow[t]{5}{*}{22} & 1 & 8 & $6 / 483499$ & 8 & 8 & $8 / 889777$ \\
\hline & 2 & $6 / 320546$ & $4 / 806759$ & $6 / 283923$ & $6 / 026228$ & $6 / 36684$ \\
\hline & 3 & $8 / 060636$ & $2 / 142305$ & & $3 / 460601$ & 8 \\
\hline & 4 & 8 & & 8 & $4 / 998801$ & 8 \\
\hline & 5 & $6 / 358236$ & $6 / 136769$ & 8 & 8 & 8 \\
\hline \multirow[t]{5}{*}{23} & 1 & 20 & 20 & $10 / 01686$ & 20 & $9 / 57783$ \\
\hline & 2 & 20 & $6 / 293852$ & $9 / 744078$ & $9 / 838103$ & 9/906017 \\
\hline & 3 & $9 / 504246$ & $9 / 169353$ & $94718 / 10$ & $7 / 363516$ & $9 / 692748$ \\
\hline & 4 & $9 / 501506$ & $8 / 873589$ & $9 / 270118$ & $4 / 813124$ & $10 / 07071$ \\
\hline & 5 & $9 / 967464$ & $9 / 643543$ & 0 & $9 / 70679$ & 9.866674 \\
\hline \multirow[t]{5}{*}{24} & 1 & 20 & $8 / 269161$ & $10 / 01686$ & 0 & $9 / 57783$ \\
\hline & 2 & $9 / 890571$ & $6 / 293852$ & $9 / 744078$ & $9 / 838103$ & 9/906017 \\
\hline & 3 & 9.504246 & $9 / 169353$ & $10 / 94718$ & 0 & $9 / 692748$ \\
\hline & 4 & 9.501506 & $8 / 874645$ & $9 / 270118$ & $4 / 813124$ & $10 / 07043$ \\
\hline & 5 & 9.967464 & $9 / 643543$ & $12 / 95602$ & $9 / 70679$ & $9 / 873936$ \\
\hline \multirow[t]{5}{*}{25} & 1 & $1 / 498662$ & $1 / 505219$ & $1 / 497008$ & $1 / 497745$ & $1 / 490148$ \\
\hline & 2 & $1 / 495034$ & $1 / 400009$ & $1 / 42745$ & $1 / 494215$ & $1 / 557767$ \\
\hline & 3 & $1 / 488998$ & $1 / 483765$ & $1 / 511544$ & $1 / 492744$ & $1 / 491943$ \\
\hline & 4 & $1 / 488955$ & $2 / 598901$ & $1 / 48534$ & $1 / 405978$ & $1 / 497791$ \\
\hline & 5 & $1 / 496236$ & $1 / 491175$ & $1 / 486715$ & $1 / 492163$ & $1 / 494661$ \\
\hline \multirow[t]{5}{*}{26} & 1 & $1 / 498662$ & $1 / 505219$ & $1 / 497008$ & $1 / 497745$ & $1 / 490148$ \\
\hline & 2 & $1 / 495034$ & $1 / 400009$ & $1 / 492745$ & $1 / 494215$ & $1 / 495276$ \\
\hline & 3 & $1 / 488998$ & $1 / 483765$ & $1 / 511544$ & $1 / 492744$ & $1 / 491943$ \\
\hline & 4 & $1 / 488955$ & $1 / 51079$ & $1 / 48534$ & $1 / 405978$ & $1 / 497791$ \\
\hline & 5 & $1 / 496236$ & $1 / 491175$ & $1 / 486715$ & $1 / 492163$ & $1 / 494661$ \\
\hline \multirow[t]{5}{*}{27} & 1 & $1 / 498662$ & $1 / 505219$ & $1 / 497008$ & $1 / 497745$ & $1 / 490148$ \\
\hline & 2 & $1 / 495034$ & $1 / 400009$ & $1 / 492745$ & $1 / 494215$ & $1 / 495276$ \\
\hline & 3 & $1 / 488998$ & $1 / 483765$ & $1 / 511544$ & $1 / 492744$ & $1 / 491943$ \\
\hline & 4 & $1 / 488955$ & $2 / 913879$ & $1 / 48534$ & $1 / 405978$ & $1 / 497791$ \\
\hline & 5 & $1 / 496236$ & $1 / 491175$ & $1 / 486715$ & $1 / 492163$ & $1 / 494661$ \\
\hline \multirow[t]{5}{*}{28} & 1 & $1 / 498662$ & $1 / 505219$ & $1 / 497008$ & $1 / 497745$ & $1 / 490148$ \\
\hline & 2 & $1 / 495034$ & $1 / 400009$ & $1 / 492745$ & $1 / 494215$ & $1 / 495276$ \\
\hline & 3 & $1 / 488998$ & $1 / 483765$ & $1 / 511544$ & $1 / 492744$ & $1 / 491943$ \\
\hline & 4 & $1 / 488955$ & $1 / 510182$ & $1 / 48534$ & $1 / 405978$ & $1 / 497791$ \\
\hline & 5 & $1 / 496236$ & $1 / 491175$ & $1 / 486715$ & $1 / 492163$ & $1 / 494661$ \\
\hline \multirow[t]{5}{*}{29} & 1 & $1 / 498662$ & $1 / 505219$ & $1 / 497008$ & $1 / 497745$ & $1 / 490148$ \\
\hline & 2 & $1 / 495034$ & $1 / 400009$ & $1 / 492745$ & $1 / 494215$ & $1 / 495276$ \\
\hline & 3 & $1 / 488998$ & $1 / 483765$ & $1 / 511544$ & $1 / 492744$ & $1 / 491943$ \\
\hline & 4 & $1 / 488955$ & $1 / 513149$ & $1 / 48534$ & $1 / 405978$ & $1 / 497791$ \\
\hline & 5 & $1 / 496236$ & $1 / 491175$ & $1 / 486715$ & $1 / 492163$ & $1 / 494661$ \\
\hline \multirow[t]{5}{*}{30} & 1 & $1 / 498662$ & $1 / 505219$ & $1 / 497008$ & $1 / 497745$ & $1 / 490148$ \\
\hline & 2 & $1 / 495034$ & $1 / 400009$ & $1 / 492745$ & $1 / 494215$ & $1 / 495276$ \\
\hline & 3 & $1 / 488998$ & $1 / 483765$ & $1 / 511544$ & $1 / 492744$ & $1 / 491943$ \\
\hline & 4 & $1 / 488955$ & $1 / 478955$ & $1 / 48534$ & $1 / 405978$ & $1 / 497791$ \\
\hline & 5 & $1 / 496236$ & $1 / 491175$ & $1 / 486715$ & $1 / 492163$ & $1 / 494661$ \\
\hline 31 & 1 & $6 / 378581$ & 8 & $6 / 352118$ & $24 / 84862$ & $6 / 242361$ \\
\hline
\end{tabular}


Reactive Power Market-Management Considering Uncertainties of Load and Power of Wind Powerhouses

\begin{tabular}{|l|c|c|c|c|c|c|}
\hline & 2 & $3 / 91243$ & 8 & $6 / 283923$ & $6 / 307429$ & $6 / 324408$ \\
\hline & 3 & $6 / 223965$ & $6 / 140242$ & $6 / 584699$ & $6 / 2 / 6467$ & $6 / 309286$ \\
\hline & 4 & $6 / 22328$ & $6 / 06572$ & $6 / 165433$ & $4 / 89565$ & $6 / 364653$ \\
\hline & 5 & $6 / 33977$ & $6 / 258789$ & $6 / 187441$ & $6 / 419591$ & $6 / 314572$ \\
\hline 32 & 1 & 8 & 8 & $6 / 352118$ & $6 / 368514$ & $6 / 242361$ \\
\hline & 2 & $6 / 133529$ & $4 / 84602$ & $6 / 283923$ & $6 / 307429$ & $6 / 324408$ \\
\hline & 3 & $6 / 223965$ & $6 / 140242$ & $6 / 584699$ & $6 / 283906$ & $40 / 13539$ \\
\hline & 4 & $6 / 22328$ & $6 / 066572$ & $6 / 165433$ & $4 / 89565$ & $6 / 364653$ \\
\hline & 5 & $6 / 33977$ & $6 / 258789$ & $6 / 187441$ & $6 / 274601$ & $6 / 314572$ \\
\hline & 1 & $8 / 514342$ & $6 / 660135$ & $8 / 408489$ & $8 / 455704$ & $7 / 969461$ \\
\hline & 2 & $7 / 909211$ & $4 / 685483$ & $8 / 135708$ & $8 / 229734$ & $8 / 297648$ \\
\hline & 3 & $7 / 895876$ & $7 / 728784$ & $9 / 338813$ & $8 / 921892$ & $8 / 084379$ \\
\hline & 4 & $7 / 893137$ & $7 / 431745$ & $7 / 771034$ & $6 / 352142$ & $8 / 458627$ \\
\hline
\end{tabular}

\section{Generative reactive power of thermal units in the third area}

\begin{tabular}{|c|c|c|c|c|c|c|}
\hline 1 & 1 & 10 & 10 & 10 & $2 / 26461$ & 10 \\
\hline & 2 & 10 & 10 & 10 & 10 & 10 \\
\hline & 3 & 10 & 10 & 10 & 10 & 10 \\
\hline & 4 & 10 & 10 & 10 & 10 & 10 \\
\hline & 5 & 10 & 10 & 10 & 10 & 10 \\
\hline \multirow[t]{5}{*}{2} & 1 & 10 & 10 & 10 & $9 / 931956$ & 10 \\
\hline & 2 & 10 & 10 & 10 & 10 & 10 \\
\hline & 3 & 10 & 10 & 10 & 10 & 10 \\
\hline & 4 & 10 & 10 & 10 & 10 & 10 \\
\hline & 5 & 10 & 10 & 10 & 10 & 10 \\
\hline \multirow[t]{5}{*}{3} & 1 & 30 & 30 & 30 & 30 & 30 \\
\hline & 2 & 30 & 30 & 30 & 30 & 30 \\
\hline & 3 & 30 & 30 & 30 & 30 & 30 \\
\hline & 4 & 30 & 30 & 30 & 30 & 30 \\
\hline & 5 & $28 / 50364$ & 30 & $19 / 8$ & 30 & 30 \\
\hline \multirow[t]{5}{*}{4} & 1 & 30 & 30 & 30 & $19 / 8$ & 30 \\
\hline & 2 & 30 & 30 & 30 & 30 & 30 \\
\hline & 3 & 30 & 30 & 30 & 30 & 30 \\
\hline & 4 & 30 & 30 & 30 & 30 & 30 \\
\hline & 5 & 30 & 30 & 30 & 30 & 30 \\
\hline \multirow[t]{5}{*}{5} & 1 & 10 & 10 & 10 & $9 / 089431$ & 10 \\
\hline & 2 & 10 & 10 & 10 & 10 & 10 \\
\hline & 3 & 10 & 10 & 10 & 10 & 10 \\
\hline & 4 & 10 & 10 & 10 & 10 & 10 \\
\hline & 5 & 10 & 10 & 10 & 10 & 10 \\
\hline \multirow[t]{5}{*}{6} & 1 & 10 & 10 & 10 & $9 / 948284$ & 10 \\
\hline & 2 & 10 & 10 & 10 & 10 & 10 \\
\hline & 3 & 10 & 10 & 10 & 10 & 10 \\
\hline & 4 & 10 & 10 & 10 & 10 & 10 \\
\hline & 5 & 10 & 10 & 10 & 10 & 10 \\
\hline \multirow[t]{5}{*}{7} & 1 & 30 & 30 & 30 & 30 & 30 \\
\hline & 2 & 30 & 30 & 30 & 30 & 30 \\
\hline & 3 & 30 & 30 & 30 & 30 & 30 \\
\hline & 4 & 30 & 30 & 30 & 30 & 30 \\
\hline & 5 & 30 & 30 & 30 & 30 & 30 \\
\hline \multirow[t]{5}{*}{8} & 1 & 30 & 30 & 30 & 30 & 30 \\
\hline & 2 & $27 / 29923$ & 30 & 30 & 30 & 30 \\
\hline & 3 & 30 & 30 & 30 & 30 & 30 \\
\hline & 4 & 30 & 30 & 30 & 30 & 30 \\
\hline & 5 & 30 & 30 & 30 & 30 & 30 \\
\hline \multirow[t]{3}{*}{9} & 1 & $23 / 98235$ & $2 / 592874$ & $3 / 257533$ & 60 & $3 / 422331$ \\
\hline & 2 & $15 / 42051$ & 0 & $2 / 175198$ & $16 / 71302$ & $12 / 73655$ \\
\hline & 3 & $39 / 6$ & $14 / 21405$ & 0 & $0 / 444243$ & $15 / 51827$ \\
\hline
\end{tabular}


Reactive Power Market-Management Considering Uncertainties of Load and Power of Wind Powerhouses

\begin{tabular}{|c|c|c|c|c|c|c|}
\hline & 4 & $39 / 6$ & $11 / 19298$ & $56 / 15606$ & $14 / 9204$ & $39 / 6$ \\
\hline & 5 & 0 & $14 / 87355$ & 0 & $39 / 6$ & $7 / 761189$ \\
\hline \multirow{5}{*}{10} & 1 & $17 / 84735$ & $8 / 067463$ & $12 / 57559$ & $9 / 035753$ & $39 / 6$ \\
\hline & 2 & $42 / 15009$ & 0 & $16 / 35313$ & $16 / 71302$ & $24 / 53061$ \\
\hline & 3 & & $28 / 89607$ & $27 / 5012$ & $0 / 093431$ & \\
\hline & 4 & $1 / 274111$ & $7 / 254989$ & 0 & 0 & $30 / 47634$ \\
\hline & 5 & $28 / 35456$ & $44 / 3198$ & $39 / 6$ & $2 / 37258$ & $6 / 113233$ \\
\hline \multirow[t]{5}{*}{11} & 1 & $4 / 315752$ & $8 / 150906$ & $39 / 6$ & $39 / 6$ & $32 / 0035$ \\
\hline & 2 & $5 / 610634$ & 0 & $39 / 09702$ & $37 / 91553$ & $39 / 6$ \\
\hline & 3 & $30 / 82615$ & $34 / 41959$ & $39 / 6$ & 60 & $16 / 10015$ \\
\hline & 4 & $40 / 98505$ & $8 / 57052$ & $28 / 82867$ & $5 / 726983$ & \\
\hline & 5 & $39 / 6$ & $13 / 41545$ & $39 / 6$ & $4 / 403454$ & $16 / 79207$ \\
\hline \multirow[t]{5}{*}{12} & 1 & 0 & $14 / 27985$ & $7 / 607862$ & 0 & $7 / 498105$ \\
\hline & 2 & $2 / 11972$ & & $7 / 539666$ & $7 / 563173$ & $7 / 580151$ \\
\hline & 3 & $7 / 479708$ & $10 / 63278$ & $8 / 236827$ & $11 / 51999$ & $11 / 15617$ \\
\hline & 4 & $10 / 96493$ & $7 / 706006$ & $7 / 421177$ & 0 & $7 / 620396$ \\
\hline & 5 & $11 / 43089$ & $7 / 514533$ & $10 / 82158$ & $7 / 530344$ & $7 / 570316$ \\
\hline \multirow[t]{5}{*}{13} & 1 & $7 / 628662$ & $5 / 890031$ & $7 / 607862$ & $0 / 103775$ & $7 / 498105$ \\
\hline & 2 & $3 / 931261$ & $6 / 055878$ & $7 / 539666$ & $11 / 30153$ & $11 / 36944$ \\
\hline & 3 & $7 / 479708$ & $10 / 63278$ & $8 / 236827$ & $12 / 38966$ & $7 / 526834$ \\
\hline & 4 & $7 / 479021$ & $10 / 3381$ & $10 / 73354$ & $6 / 17039$ & $7 / 620396$ \\
\hline & 5 & $11 / 43089$ & $11 / 10697$ & $7 / 443185$ & $7 / 530344$ & $7 / 570316$ \\
\hline \multirow[t]{5}{*}{14} & 1 & $7 / 628662$ & $5 / 890031$ & $11 / 48028$ & 0 & $11 / 04126$ \\
\hline & 2 & $3 / 931261$ & $5 / 528506$ & $11 / 2075$ & $11 / 30153$ & $11 / 36944$ \\
\hline & 3 & $10 / 96767$ & $10 / 63278$ & $12 / 41061$ & $1 / 592459$ & $11 / 15617$ \\
\hline & 4 & $10 / 96493$ & $10 / 3381$ & $10 / 73354$ & $6 / 27655$ & $11 / 53226$ \\
\hline & 5 & $11 / 43089$ & $11 / 10697$ & $10 / 82158$ & $11 / 17022$ & $11 / 50687$ \\
\hline \multirow[t]{5}{*}{15} & 1 & $12 / 8461$ & $25 / 17434$ & $12 / 75546$ & 0 & $12 / 31643$ \\
\hline & 2 & $20 / 56026$ & $18 / 07448$ & $12 / 48268$ & $12 / 57948$ & $12 / 64375$ \\
\hline & 3 & 0 & $11 / 90795$ & $10 / 90057$ & $1 / 038121$ & $1 / 013884$ \\
\hline & 4 & & $5 / 566582$ & $11 / 79207$ & & $12 / 8079$ \\
\hline & 5 & $12 / 70606$ & $0 / 367277$ & 0 & $11 / 69593$ & $21 / 31696$ \\
\hline \multirow[t]{5}{*}{16} & 1 & 6 & 6 & 6 & 6 & 6 \\
\hline & 2 & 6 & 6 & 6 & 6 & 6 \\
\hline & 3 & 6 & 6 & 6 & 6 & 6 \\
\hline & 4 & 6 & 6 & 6 & 6 & 6 \\
\hline & 5 & 6 & 6 & 6 & 6 & 6 \\
\hline \multirow[t]{5}{*}{17} & 1 & 6 & 6 & 6 & 6 & 6 \\
\hline & 2 & 6 & 6 & 6 & 6 & 6 \\
\hline & 3 & 6 & 6 & 6 & 6 & 6 \\
\hline & 4 & 6 & 6 & 6 & 6 & 6 \\
\hline & 5 & 6 & 6 & 6 & 6 & 6 \\
\hline \multirow[t]{5}{*}{18} & 1 & 6 & 6 & 6 & 6 & 6 \\
\hline & 2 & 6 & 6 & 6 & 6 & 6 \\
\hline & 3 & 6 & 6 & 6 & 6 & 6 \\
\hline & 4 & 6 & 6 & 6 & 6 & 6 \\
\hline & 5 & 6 & 6 & 6 & 6 & 6 \\
\hline \multirow[t]{5}{*}{19} & 1 & 6 & 6 & 6 & 6 & 6 \\
\hline & 2 & 6 & 6 & 6 & 6 & 6 \\
\hline & 3 & 6 & 6 & 6 & 6 & 6 \\
\hline & 4 & 6 & 6 & 6 & 6 & 6 \\
\hline & 5 & 6 & 6 & 6 & 6 & 6 \\
\hline \multirow[t]{5}{*}{20} & 1 & 6 & 6 & 6 & 6 & 6 \\
\hline & 2 & 6 & 6 & 6 & 6 & 6 \\
\hline & 3 & 6 & 6 & 6 & 6 & 6 \\
\hline & 4 & 6 & 6 & 6 & 6 & 6 \\
\hline & 5 & 6 & 6 & 6 & 6 & 6 \\
\hline \multirow[t]{2}{*}{21} & 1 & $11 / 58614$ & $3 / 996398$ & $12 / 28585$ & 0 & $11 / 04126$ \\
\hline & 2 & $17 / 71411$ & $5 / 528506$ & $20 / 34017$ & $11 / 30153$ & $11 / 23742$ \\
\hline
\end{tabular}


Reactive Power Market-Management Considering Uncertainties of Load and Power of Wind Powerhouses

\begin{tabular}{|c|c|c|c|c|c|c|}
\hline & 3 & $10 / 83565$ & $10 / 50076$ & $13 / 54865$ & $11 / 13949$ & $11 / 02416$ \\
\hline & 4 & $10 / 83291$ & $10 / 20606$ & $10 / 60153$ & $6 / 220517$ & $11 / 40166$ \\
\hline & 5 & $12 / 02924$ & $11 / 39769$ & $7 / 056832$ & $52 / 8$ & $20 / 58682$ \\
\hline \multirow[t]{5}{*}{22} & 1 & $8 / 197289$ & 0 & $11 / 34827$ & $4 / 233524$ & $10 / 90924$ \\
\hline & 2 & 0 & $9 / 714886$ & $11 / 07548$ & $11 / 16951$ & $5 / 400681$ \\
\hline & 3 & $10 / 83565$ & $10 / 50076$ & $17 / 4216$ & $8 / 954982$ & $21 / 3406$ \\
\hline & 4 & $13 / 43908$ & 80 & $11 / 66823$ & $52 / 8$ & $13 / 65218$ \\
\hline & 5 & $15 / 43127$ & $11 / 37191$ & $11 / 88453$ & $10 / 23127$ & $13 / 7657$ \\
\hline \multirow[t]{5}{*}{23} & 1 & $13 / 70412$ & $22 / 36815$ & $25 / 68172$ & $14 / 73521$ & $12 / 31643$ \\
\hline & 2 & $19 / 47012$ & 132 & $12 / 48268$ & $12 / 57951$ & $12 / 60349$ \\
\hline & 3 & $27 / 54533$ & $11 / 90795$ & 0 & $7 / 81825$ & $12 / 49511$ \\
\hline & 4 & 0 & $16 / 6388$ & 0 & 0 & $5 / 843181$ \\
\hline & 5 & 0 & 0 & 0 & 0 & 0 \\
\hline \multirow[t]{5}{*}{24} & 1 & $10 / 58841$ & $22 / 3874$ & 0 & $12 / 61678$ & 0 \\
\hline & 2 & $4 / 890317$ & 0 & $8 / 795081$ & & 0 \\
\hline & 3 & 0 & 0 & 0 & $1 / 038121$ & 0 \\
\hline & 4 & 0 & $2 / 733537$ & 0 & 0 & 0 \\
\hline & 5 & 0 & 0 & 0 & 0 & 0 \\
\hline \multirow[t]{5}{*}{25} & 1 & 16 & 16 & 16 & 16 & 16 \\
\hline & 2 & 16 & 16 & 16 & 16 & $15 / 43593$ \\
\hline & 3 & 16 & 16 & 16 & 16 & 16 \\
\hline & 4 & 16 & $5 / 0136$ & 16 & 16 & 16 \\
\hline & 5 & 16 & 16 & 16 & 16 & 16 \\
\hline \multirow[t]{5}{*}{26} & 1 & 16 & 16 & 16 & 16 & 16 \\
\hline & 2 & 16 & 16 & 16 & 16 & 16 \\
\hline & 3 & 16 & 16 & 16 & 16 & 16 \\
\hline & 4 & 16 & $3 / 276083$ & 16 & 16 & 16 \\
\hline & 5 & 16 & 16 & 16 & 16 & 16 \\
\hline \multirow[t]{5}{*}{27} & 1 & 16 & 16 & 16 & 16 & 16 \\
\hline & 2 & 16 & 16 & 16 & 16 & 16 \\
\hline & 3 & 16 & 16 & 16 & 16 & 16 \\
\hline & 4 & 16 & 16 & 16 & 16 & 16 \\
\hline & 5 & 16 & 16 & 16 & 16 & 16 \\
\hline \multirow[t]{5}{*}{28} & 1 & 16 & 16 & 16 & 16 & 16 \\
\hline & 2 & 16 & 16 & 16 & $13 / 40958$ & 16 \\
\hline & 3 & 16 & 16 & 16 & 16 & 16 \\
\hline & 4 & 16 & $15 / 25364$ & 16 & 16 & 16 \\
\hline & 5 & 16 & 16 & 16 & 16 & 16 \\
\hline \multirow[t]{5}{*}{29} & 1 & 16 & 16 & 16 & 16 & 16 \\
\hline & 2 & 16 & 16 & 16 & 16 & 16 \\
\hline & 3 & 16 & 16 & 16 & 16 & 16 \\
\hline & 4 & 16 & $15 / 07405$ & 16 & 16 & 16 \\
\hline & 5 & 16 & 16 & 16 & 16 & 16 \\
\hline \multirow[t]{5}{*}{30} & 1 & $15 / 32856$ & 16 & 16 & 16 & 16 \\
\hline & 2 & 16 & 16 & 16 & 16 & 16 \\
\hline & 3 & 16 & 16 & 16 & 16 & 16 \\
\hline & 4 & 16 & $15 / 65943$ & 16 & 16 & 16 \\
\hline & 5 & 16 & 16 & 16 & 16 & 16 \\
\hline \multirow[t]{5}{*}{31} & 1 & $11 / 45412$ & $12 / 2 / 751$ & $11 / 34827$ & $2 / 156788$ & $10 / 90924$ \\
\hline & 2 & $11 / 24635$ & $5 / 553086$ & $11 / 07548$ & $11 / 17199$ & $8 / 293303$ \\
\hline & 3 & $14 / 39312$ & $14 / 05823$ & $17 / 4216$ & $16 / 38074$ & $15 / 36229$ \\
\hline & 4 & $14 / 39038$ & $13 / 76354$ & $14 / 19552$ & $9 / 155849$ & $15 / 03163$ \\
\hline & 5 & $14 / 83814$ & $14 / 49985$ & $14 / 24703$ & $15 / 67688$ & $15 / 03608$ \\
\hline \multirow[t]{5}{*}{32} & 1 & $9 / 141364$ & 0 & $14 / 90573$ & $13 / 46452$ & $14 / 46671$ \\
\hline & 2 & $14 / 37261$ & $9 / 27579$ & $14 / 58371$ & $14 / 73024$ & $14 / 80537$ \\
\hline & 3 & $14 / 39312$ & $14 / 05823$ & $17 / 4216$ & $52 / 8$ & $15 / 0504$ \\
\hline & 4 & $14 / 39038$ & $13 / 76354$ & $13 / 7521$ & $3 / 721847$ & $15 / 03163$ \\
\hline & 5 & $14 / 83814$ & $12 / 33269$ & $14 / 24703$ & $14 / 86761$ & $25 / 52904$ \\
\hline 33 & 1 & $8 / 276157$ & $29 / 34386$ & 0 & $2 / 389339$ & 0 \\
\hline
\end{tabular}


Reactive Power Market-Management Considering Uncertainties of Load and Power of Wind Powerhouses

\begin{tabular}{|c|c|c|c|c|c|c|}
\hline & 2 & 0 & $5 / 664329$ & 0 & 0 & 0 \\
\hline & 3 & 0 & 0 & 0 & $0 / 583943$ & 0 \\
\hline & 4 & $8 / 287599$ & $4 / 305802$ & 0 & 99 & 0 \\
\hline & 5 & 0 & 0 & 0 & 0 & $11 / 59563$ \\
\hline
\end{tabular}

REFERENCES

[1] M.L. Baughman, and S.N. Siddiqi, "Real-time pricing of reactive power: theory and case study results," IEEE Transactions on Power Systems, vol. 6(1), pp. 23-29, Feb. 1991.

[2] A.A. El-Keib, and X. Ma, "Calculating short-run marginal costs of active and reactive power production," IEEE Transactions on Power Systems, vol. 12(2), pp. 559-565, May. 1997.

[3] N.H. Dandanchi, M.J. Rawlins, O. Alsac, M. Prais and B. Stott, "OPF for reactive pricing studies on the NGC system," IEEE Transactions on Power Systems, vol. 11(1), pp. 226-232, May. 1996.

[4] W.-C. Chu, Bin-Kwie Chen, and Chung-Hsien Liao, "Allocating the costs of reactive power purchased in an ancillary service market by modified Y-Bus matrix method," IEEE Transactions on Power System, vol. 19(1), pp. 174-179, Feb. 2004.

[5] X.J. Lin, C.W. Yu, N.Xu, C.Y. Chung, and H. Wu, "Reactive power service cost allocation using Aumann-Shapley method," IEEE Proceeding on Generation Transmission and Distribution, vol. 153(5), pp. 379-387, September. 2006.

[6] K.L. Lo, and Y.A. Alturki, "Towards reactive power markets.Part 1: Reactive power allocation," IEEE Proceeding on Generation Transmission and Distribution, vol. 153 (1), pp. 59-70, Jan. 2006.

[7] E. De Tuglie, and F. Torelli, "Distribution factor for reactive power in the presence of bilateral transactions," IEEE Proceedings on Generation Transmission and Distribution, vol. 151(3), pp. 379-387, May. 2004.

[8] M.J. Rider, and V.L. Paucar, "Application of a nonlinear reactive power pricing model for competitive electric market," IEEE Proceedings on Generation Transmission and Distribution, vol. 151(3), pp. 407414, May. 2004.

[9] V.M. Dona, and A.N. Paredes, "Reactive power pricing in competitive electric markets using the transmission losses function," IEEE Porto Power Tech Conference, vol. 1, pp. 6, 2001.

[10] S. Ahmed, and G. Strbac, "A method for simulation and analysis of reactive power market," IEEE Transactions on Power Systems, vol. 15(3), pp.1047-1052, Aug. 2000.

[11] D.J. Burke, and M.J. O'Malley, "Optimal firm wind capacity allocation to power systems with security constraints," Power Systems Conference and Exposition, pp. 1-9, March. 2009.

[12] G.E.P. Box, G.M. Jenkins \& G.C. Reinsel, "Time Series Analysis; Forecasting and Contrlo.3rdedn.Prentice-Hall, Englewood Cliffs.

[13] Generalized Algebraic Modeling Systems (GAMS), [Online] Available: http://www.gams.com.

[14] Hao, S., \&Papalexopoulos, A. (1997). Reactive power pricing and management . IEEE transactions on Power Systems, 12(1), 95-104.

[15] X. Cheng, F. C. Huff, and P. Francino, "Optimal load dispatch based on generator reactive capability curve, " presented at the Power Engineering Society General Meeting, 2006. IEEE, Montreal, Que., 2006.

[16] W. Lamont and J. Fu, "Cost analysis of reactive power support, " Power Systems, IEEE Transactions on, vol. 14, pp. 890-898 2002.

[17] Dai, Y., Ni, Y.X., Wen, F.S., \& Han, Z.X. (2000). Analysis of reactive power pricing under deregulation. IEEE Power Engineering Society Summer Meeting 2004, vol. 4, 2162-2167.

[18] Valverde, G., \& Orozco, J.J. (2014). Reactive Power Limits in Distributed Generators from Generic Capability Curves. In PES General Meeting Conference \& Exposition, IEEE, 1-5.

[19] Cutsem, T.V., \&Vournas, C. (1998). Voltage Stability of Electric Power Systems. Springer.

[20] Ghennam, T., Aliouane, K., Akel, F., Francois, B., \&Berkouk, E.M. (2015). Advanced control system of DFIG based wind generators for reactive power production and integration in a wind farm dispatching. Energy Conversion and Management, 105, 240-250.

[21] Chowdhury, M.A., Shen, W.X., Hosseinzadeh, N., \&Pota, H.R. (2013). A novel aggregated DFIG wind farm model using mechanical torque compensating factor. Energy Convers Manage, 67, 265-274.

[22] FeshkiFarahani, H., Shayanfar, H.A., \&Ghazizadeh, M.S. (2014). Modeling of stochastic behavior of plugin hybrid electric vehicle in a reactive power market. Electrical Engineering, 96(1), 1-13.

[23] Turitsyn, K., Sulc, P., Backhaus, S., \&Chertkov, M. (2011). Options for control of reactive power by distributed photovoltaic generators. Proc. IEEE, 99(6), 1063-1073. 
[24] Carvalho, P.M.S., COrreia, P.F., \& Ferreira, L.A. (2008). Distributed reactive power generation control for voltage rise mitigation in distribution networks. IEEE Trans. Power Syst., 23(2), 766-772.

[25] Kekatos, V., Wang, G., Conejo, A. J., \&Giannakis, G. B. (2015). Stochastic reactive power management in microgrids with renewables. IEEE Transactions on Power Systems, 30(6), 3386-3395.

[26] Saraswat, A., Saini, A., \&Saxena, K. (2013). A novel multi-zone reactive power market settlement model: A pareto-optimization approach. Energy, 51(C), 85-100.

[27] Bolognani, S., \&Zampieri, S. (2013). A distributed control strategy for reactive power compensation in smart microgrids. IEEE Transactions on Automatic Control, 58(11), 2818-2833.

Citation: Akbar Sharifi Ziarati \& Mojtaba Najafi (2017). Reactive Power Market-Management Considering Uncertainties of Load and Power of Wind Powerhouses, International Journal of Research Studies in Electrical and Electronics Engineering (IJRSEEE), 3(3), pp.33-58, DOI: http://dx.doi.org/10.204 31/24549436.0303004.

Copyright: (C) 2017 Akbar Sharifi Ziarati \& Mojtaba Najafi. This is an open-access article distributed under the terms of the Creative Commons Attribution License, which permits unrestricted use, distribution, and reproduction in any medium, provided the original author and source are credited 